\title{
National Estimates of Gross Employment and Job Flows from the Quarterly Workforce Indicators with Demographic and Industry Detail
}

\author{
John M. Abowd and Lars Vilhuber \\ School of Industrial and Labor Relations, Cornell University, Ithaca, NY 14853
}

\begin{abstract}
The Quarterly Workforce Indicators (QWI) are local labor market data produced and released every quarter by the United States Census Bureau. Unlike any other local labor market series produced in the U.S. or the rest of the world, QWI measure employment flows for workers (accession and separations), jobs (creations and destructions) and earnings for demographic subgroups (age and gender), economic industry (NAICS industry groups), detailed geography (block (experimental), county, Core-Based Statistical Area, and Workforce Investment Area), and ownership (private, all) with fully interacted publication tables. The current QWI data cover 47 states, about $98 \%$ of the private workforce in those states, and about $92 \%$ of all private employment in the entire economy. State participation is sufficiently extensive to permit us to present the first national estimates constructed from these data. We focus on worker, job, and excess (churning) reallocation rates, rather than on levels of the basic variables. This permits comparison to existing series from the Job Openings and Labor Turnover Survey and the Business Employment Dynamics Series from the Bureau of Labor Statistics (BLS). The national estimates from the QWI are an important enhancement to existing series because they include demographic and industry detail for both worker and job flow data compiled from underlying micro-data that have been integrated at the job and establishment levels by the Longitudinal Employer-Household Dynamics Program at the Census Bureau. The estimates presented herein were compiled exclusively from public-use data series and are available for download.
\end{abstract}

\section{JEL Classifications}

J6; C82; C43

\footnotetext{
(C) 2010 Elsevier B.V. All rights reserved.

Correspondence to john.abowd@cornell.edu.

Publisher's Disclaimer: This is a PDF file of an unedited manuscript that has been accepted for publication. As a service to our customers we are providing this early version of the manuscript. The manuscript will undergo copyediting, typesetting, and review of the resulting proof before it is published in its final citable form. Please note that during the production process errors may be discovered which could affect the content, and all legal disclaimers that apply to the journal pertain.

No confidential data were used in this paper. All public-use Quarterly Workforce Indicators data can be accessed from http://www.vrdc.cornell.edu/news/data/qwi-public-use-data/. The national indicators developed in this paper can be accessed from http://www.vrdc.cornell.edu/news/data/qwi-national-data/. We are grateful for the comments and suggestions of many of our colleagues, past and present, too numerous to list here and thus listed at the website above and in the working paper version of this article. The opinions expressed in this paper are those of the authors and not the U.S. Census Bureau nor any of the research sponsors.
} 


\section{Introduction}

The measurement of gross flows of workers into and out of employment has occupied applied economists for more than thirty years. For decades the Bureau of Labor Statistics (BLS) has derived these measurements from the Current Population Survey (CPS) in the United States. In other countries statistical agencies use similar instruments, usually called labor force surveys, to measure gross worker flows. ${ }^{1}$ The measurement of gross job flows has a much more recent history originating in work using American manufacturing establishments. The first direct simultaneous measurement of both worker and job flows using individual, establishment and job-level data integrated at the micro-data level were produced from French administrative and survey records. ${ }^{2}$ Aggregate estimates of worker and job flows for the U.S. have been produced by integrating tabulated data from household surveys (CPS), establishment surveys (Job Openings and Labor Turnover Survey (JOLTS)), and establishment level micro-data (BLS measures based on the Quarterly Census of Employment and Wages (QCEW)). ${ }^{3}$ Using data similar to those that form the basis for our work, integrated collections of worker and job flows have been produced for small groups of states ${ }^{4}$ and for the state of Maryland ${ }^{5}$ using Unemployment Insurance (UI) wage records as the micro-data basis.

A coherent aggregate story has emerged. Gross flows greatly exceed net flows. Furthermore, worker flows-accessions and separations-exceed job flows-creations and destructions. The magnitude of the "churning" depends upon the state of the economy, weakly, and the whether the employer is growing, staying constant, or shrinking. ${ }^{6}$ Modeling these gross flows, especially during economic downturns and for different demographic groups, has been a goal of many individual and agency researchers. Such modeling forms the basis for recent work at the $\mathrm{BLS}^{7}$ where the principle difficulty remains an inability to measure all of the flows at the same consistent microeconomic level-that of the job or employer. Only the estimates based on French employers and those using employers operating in the state of Maryland provide fully integrated microeconomic data approaches in which all of the relevant flows are measured using micro-data at the job level.

When the U.S. Census Bureau began publishing the QWI in 2003, it marked the first time that an American statistical agency had attempted to provide labor force stock, flow, and earnings data from a consistent, integrated job-level source. The system is based on the integration of demographic, economic and job-level data using state-level UI and QCEW micro-data linked to Census Bureau censuses and surveys on households and businesses (Abowd, Haltiwanger, and Lane, 2004). At first, there were only 18 participating states, representing about 30\% of the U.S. labor force. By 2009, all but two states (Massachusetts and New Hampshire) had joined the Local Employment Dynamics (LED) Federal/State Partnership that provides the data. Current published QWI data cover $92 \%$ of private nonfarm employment. Since the system was designed to provide consistent stock and flow information at very detailed geographic, industrial and demographic detail, the fact that participation by states was not universal was not seen as a serious drawback. However, now

\footnotetext{
${ }^{1}$ See Abowd and Zellner (1985) and Poterba and Summers (1986) for early discussions of the gross worker flow problem in the context of the Current Population Survey (CPS).

2 Job flow data initiated with the work of Dunne, Roberts, and Samuelson (1989) and Davis and Haltiwanger's earliest work (Davis and Haltiwanger, 1990, 1992; Davis et al., 1996). Integrated worker and job data were first produced by Abowd et al. (1999).

${ }^{3}$ See Davis, Faberman, and Haltiwanger (2006); Boon, Carson, Faberman, and Ilg (2008) and Davis, Faberman, Haltiwanger, and Rucker (forthcoming).

${ }_{5}^{4}$ See Anderson and Meyer (1994); Burgess, Lane, and Stevens (2000).

${ }^{5}$ See Burgess, Lane, and Stevens (2001).

${ }^{6}$ Churning is defined in Burgess et al. (2000). See Abowd et al. (1999) and Burgess et al. (2001) for general summaries of flow magnitudes.

${ }^{7}$ See Spletzer, Faberman, Sadeghi, Talan, and Clayton (2004) and Boon, Carson, Faberman, and Ilg (2008).
} 
that participation is essentially universal, this paper constructs national estimates, for the first time, using the same industrial and demographic detail that characterizes the original QWI publication. In addition, this paper provides evidence on the statistical reliability of the national QWI estimates and on their sensitivity to missing state data.

In section 2, we describe the basic public-use data sources that form the core of our national gross flow estimates. Section 3 provides the formulae for our worker, job, and excess reallocation rates and their components. We also describe the series from the QCEW, Business Employment Dynamics (BED), and JOLTS that we use for comparison and imputation, where needed. Section 4 describes how we handled the incomplete QWI data in forming national rates. Section 5 presents our results in both tabular and graphical form. We conclude in section 6 .

\section{Data Sources and Definitions}

\subsection{Quarterly Workforce Indicators}

The Census Bureau publishes the QWI state-by-state at the beginning of each calendar quarter for data covering the quarter that ended nine months earlier, and all earlier quarters, at lehd.did.census.gov/led/. The complete set of 30 QWI are available at the Cornell VirtualRDC for download at www.vrdc.cornell.edu/qwipu/. In this article we consider only the series pertaining to private-ownership, and we use only state-wide totals disaggregated by NAICS sector, gender and age, fully interacted. We focus on six core variables: beginning- and end-of-quarter employment (which will be denoted by $B$ and $E$, respectively), accessions $A$, separations $S$, job creations $J C$, and job destructions $J D$. To understand how the QWI relate to similar measures published by the BLS, we present a brief summary of the data integration methods and definitions here. Detailed definitions for other variables are available in Abowd, Stephens, Vilhuber, Andersson, McKinney, Roemer, and Woodcock (2009) and online at the sites noted above. We will compare the similarities and differences between QWI and BLS measures from the JOLTS, QCEW and BED below.

The fundamental data integration is performed by the Longitudinal Employer-Household Dynamics (LEHD) Program to create its infrastructure file system, which is the core database used to create the QWI. The data are provided by the LED Federal/State partnership, which currently has 48 member states, the District of Columbia, Puerto Rico and the Virgin Islands (as of October 2009). The basic linking record is the state Unemployment Insurance (UI) wage record, which records for a particular individual and legal employer (state UI account) the total UI-covered earnings by that individual paid by the legal employer during the calendar quarter. The individual identifier used in this system (an encrypted form of the Social Security Number) permits longitudinal linking of the individual. The employer identifier used in this system - an employer's state-specific UI account number - is identical to the one used on the establishment-level summary collected by state labor market information offices currently called the Quarterly Census of Employment and Wages and formerly known as the ES-202 report. However, subsequent edits in the BLS's Longitudinal Business Database (LDB) and within LEHD's data infrastructure may differ. The UI wage records and QCEW micro-data are provided to the Census Bureau with a two-quarter lag (the same reporting lag as at the BLS) as part of the LED partnership.

Demographic data (age and gender) are integrated using the individual identifier linked to other Census Bureau demographic data, primarily a Census-enhanced version of the Social Security Number database (also with encrypted identifiers). Economic data (NAICS and geography) are integrated using the employer identifier linked to a Census-enhanced version of the QCEW data called the Employer Characteristics File. For state single-unit employers 
the linkage is exact. For employers with multiple work locations, the linkage is multiply imputed (Abowd et al., 2009).

QWI data are currently available for 47 states, but availability declines as one goes back in time. For the year 2000, only 38 states have available data. Figure 1 shows QWI data availability expressed as a percentage of the QCEW month-one employment for all available states by quarter. In the earliest quarter we used (1993:Q1), about 30\% of the QCEW private employment has data in the QWI. By the end of our analysis period, 92\% of private QCEW employment is represented.

The QWI uses noise-infusion as its confidentiality-protection mechanism (see Abowd et al. $(2006,2009)$ for a fuller description). Using internally computed state-wide totals is highly accurate. Suppressions are rare even at the NAICS sector $\times$ county $\times$ gender $\times$ age group level, with far less than $1 \%$ of data items suppressed because they do not meet the Census Bureau's data publication standards and less than $0.1 \%$ of the workforce in the relevant states subject to data suppression.

\subsection{Quarterly Census of Employment and Wages}

The QCEW data are derived from employer reports for the UI systems of the states. The BLS publishes counts at the county, MSA, state, and national levels by industry at www.bls.gov/cew/. In this article, we focus on the state by NAICS sector tabulations for private employment. There are some suppressions at this level, but less than $1 \%$ of the values and less than $0.1 \%$ of employment are suppressed during the entire period used here. In this article, we use data from $1992: Q 4$ through $2008: Q 4 .{ }^{8}$ The QCEW tabulations report monthly employment levels as of the payroll period covering the $12^{\text {th }}$ calendar day in each month. We refer to the tabulation for the first month of the quarter as the QCEW month-1 employment. Similarly, we refer to the tabulation for the payroll period covering the $12^{\text {th }}$ calendar day of the third month of the quarter as the QCEW month-3 employment.

\subsection{Business Employment Dynamics}

The BED data are released quarterly by the BLS at www.bls.gov/bdm/. The focus is on gross job creation and destruction at the establishment level. Gross job gains (creations) and losses (destructions) data are available at the state, (approximate) NAICS sector, and size class level. None of the two- or three-way interactions of those variables are published. Establishment-based counts are available at the NAICS sector level. There are no missing or suppressed values in the public-use data; however, some NAICS sectors have been collapsed: sectors 11-21 (natural resources and mining), 53-56 (professional and business services), as well as 71-72 (leisure and hospitality services) are thus not separately available. In this article, we use data on private employment from $1993: Q 1$ through 2008 : Q4. ${ }^{9}$

\subsection{Job Openings and Labor Turnover Survey}

The JOLTS data are collected from a monthly establishment survey conducted by the BLS covering private nonfarm establishments. The BLS publishes JOLTS data at aggregated NAICS sector and Census Region levels at www.bls.gov/jlt/. Data are collected for continuing establishments for total employment, job openings, hires, quits, layoffs, discharges, and other separations. The employment report is based on employees on payroll in the pay period that includes the $12^{\text {th }}$ calendar day of the reference month. Hires in JOLTS correspond to accessions in QWI, namely, the total number of additions to the payroll at any

\footnotetext{
${ }^{8}$ Data as provided by ftp://ftp.bls.gov/pub/special.requests/cew/ on 2009-10-09.

${ }^{9}$ Data as provided by ftp://ftp.bls.gov/pub/time.series/bd/ on 2009-10-09.
} 
time during the reference month. Total separations in JOLTS are the total number of terminations at any time during the reference month from quits, layoffs, discharges, and other reasons. We use monthly JOLTS data for private employment aggregated to calendar quarter from $2001: Q 1$ through $2009: Q 2{ }^{10}$

\section{Gross Reallocation Rate Definitions}

In this section we define all of the reallocation measures that we have created from the national QWI. In addition, we define the comparison measures that we have constructed from the QCEW and BED. For the QWI we use the following categories: for age groups, $a=$ $0,1, \ldots, 8$ (all, 14-18, 19-21, 22-24, 25-34, 35-44, 45-54, 55-64, 65+); for gender groups, $g=0,1,2$ (both, male, female); for industries, $k=11,21, \ldots, 81$ (19 NAICS sectors defined consistent with the Census Bureau's NAICS standard for the QWI and reported with customized aggregates for the BED by BLS); for the states $s=01, \ldots, 56$ (50 states, excluding DC, using FIPS codes), and, finally, the time index $t=1993: Q 1-2008: Q 4 .{ }^{11}$ Since gross job flows are defined only at an establishment (and not at an individual) level, we need to explicitly include the codes for the marginal categories in the definitions of the indices for demographic categories. We elaborate on this requirement below.

\subsection{Gross Worker Flow Measures}

Gross worker flows are measured using the Worker Reallocation Rate $\left(W R R_{\text {agkst }}\right)$ :

$$
W R R_{a g k s t}=\frac{A_{a g k s t}+S_{a g k s t}}{\left(B_{a g k s t}+E_{a g k s t}\right) / 2}
$$

where

$$
\begin{aligned}
& A_{\text {agkst }} \equiv \text { accessions (new hires plus recalls) } \\
& S_{\text {agkst }} \equiv \text { separations (quits, layoffs, other) } \\
& B_{\text {agkst }} \equiv \text { beginning-of-quarter employment } \\
& E_{\text {agkst }} \equiv \text { end-of-quarter employment. }
\end{aligned}
$$

$W R R$ measures total accession and separation flows as a proportion of average employment over the quarter in the age, gender, industry and state. The $W R R$, and all the reallocation measures used in this paper, is a symmetric growth rate designed to approximate the logarithmic change over the time period (one quarter). In addition, the $W R R$, and all of the reallocation measures used in this paper, can be expressed as the sum of its inflow and outflow components, the distinct accession and separation rates are defined, respectively, as:

$$
A R_{a g k s t}=\frac{A_{\text {agkst }}}{\left(B_{\text {agkst }}+E_{\text {agkst }}\right) / 2}
$$

and

\footnotetext{
${ }^{10}$ Data as provided by ftp://ftp.bls.gov/pub/time.series/jt/ on 2009-10-15.

${ }^{11}$ In the construction of the QWI, data from three successive quarters are required to compute all of the measures we use in this paper. Hence, we use data from 2008:Q4 but our reported measures stop in 2008:Q3 because 2009:Q1 was not available at the time we performed these calculations.
} 


$$
S R_{a g k s t}=\frac{S_{a g k s t}}{\left(B_{a g k s t}+E_{a g k s t}\right) / 2} .
$$

Details on the timing and construction of the basic QWI employment stock and flow measures used to define all of our reallocation rates can be found in Abowd et al. (2009). Methodological issues associated with inaccuracies in the individual identifers are discussed in Abowd and Vilhuber (2005). Dynamic linking of UI and QCEW firms and establishments is discussed in Benedetto, Haltiwanger, Lane, and McKinney (2007) for QWI and the LEHD infrastructure files, and in Pivetz, Searson, and Spletzer (2001) for the LDB, which is the micro-data source for the BED and is derived from the QCEW.

Essential details for the QWI are summarized here. When an individual/employer pair have a record in the UI wage record data, an indicator variable $m_{i j t}=1$ is recorded for individual $i$ at employer $j$ in quarter $t$, otherwise, $m_{i j t}=0$. Beginning-of-quarter employment is the count of all individuals working at a particular establishment for whom $m_{i j t-1}=1$ and $m_{i j t}=1$; that is, the individual and employer had a UI wage record for the current quarter $(t)$ and the previous quarter $(t-1) .{ }^{12}$ Similarly, end-of-quarter employment is the count of all individuals working at a particular establishment for whom $m_{i j t}=1$ and $m_{i j t+1}=1$; that is, the individual and employer had a UI wage record for the current quarter $(t)$ and the next quarter $(t+1)$. An accession in quarter $t$ occurs when $m_{i j t-1}=0$ and $m_{i j t}=1$. A separation in quarter $t$ occurs when $m_{i j t}=1$ and $m_{i j t+1}=0$. Workplace characteristics are defined by the NAICS code and physical address of establishment $j$ for the QCEW report at quarter $t$. Demographic characteristics are defined by the individual's gender and age as of the first day of the quarter. Accessions and separations satisfy the net job flow $\left(J F_{\text {agkst }}\right)$ identity

$$
J F_{\text {agkst }} \equiv E_{\text {agkst }}-B_{\text {agkst }}=A_{\text {agkst }}-S_{\text {agkst }} .
$$

\subsection{Gross Job Flow Measures}

Gross job flows are measured in similar fashion using the symmetric Job Reallocation Rate $\left(J R R_{\text {agkst }}\right)$

$$
J R R_{a g k s t}=\frac{J C_{a g k s t}+J D_{a g k s t}}{\left(B_{a g k s t}+E_{a g k s t}\right) / 2}
$$

where

$$
\begin{aligned}
& J C_{\text {agkst }} \equiv \text { job creations } \\
& J D_{\text {agkst }} \equiv \text { job destructions. }
\end{aligned}
$$

$J R R$ measures total job creations and destructions (called job creations/destructions in the QWI and gross job gains/losses in the BED) as a proportion of average employment over the quarter in the category. The gross job inflow and outflow rates, the Job Creation Rate (JCR) and Job Destruction Rate $(J D R)$, can be defined as additive components of the JRR:

\footnotetext{
${ }^{12}$ The QWI tabulations consider a wage record to be present in a given quarter if and only if at least $\$ 1.00$ of covered UI wages are reported in that quarter.
} 


$$
J C R_{a g k s t}=\frac{J C_{a g k s t}}{\left(B_{a g k s t}+E_{a g k s t}\right) / 2}
$$

and

$$
J D R_{a g k s t}=\frac{J D_{a g k s t}}{\left(B_{a g k s t}+E_{a g k s t}\right) / 2} .
$$

Gross job flow measures are defined at an establishment, not job, level. Let $B_{a g j t}$ be beginning-of-quarter employment for demographic group ag at establishment $j$ in quarter $t$, and similarly let $E_{a g j t}$ be end-of-quarter employment for the same category and time period. Then,

$$
\begin{aligned}
& J C_{a g j t} \equiv \max \left(E_{a g j t}-B_{a g j t}, 0\right) \\
& J D_{a g j t} \equiv \max \left(B_{a g j t}-E_{a g j t}, 0\right)
\end{aligned}
$$

so that, as originally specified by Davis and Haltiwanger, job creations are the change in employment when employment is growing at the establishment and job destructions are the change in employment when employment is shrinking at the establishment. Net job flows also satisfy the identity

$$
J F_{a g k s t}=J C_{a g k s t}-J D_{a g k s t}
$$

\subsection{Excess Flow Measures}

Finally, we define the excess reallocation measured using the symmetric Excess Reallocation Rate $\left(E R R_{\text {agkst }}\right)$

$$
E R R_{a g k s t}=W R R_{a g k s t}-J R R_{a g k s t}
$$

which measures the difference between gross worker flow and gross job flow rates, sometimes called the labor market "churning" rate (Burgess et al., 2000). The ERR measures the rate of gross worker flow activity in each category in excess of the minimum rate required to account for the observed gross job reallocation. Separate inflow and outflow excess reallocation rates can be defined using the components of the ERR-specifically, the Excess Inflow Rate $(E I R)$ and the Excess Outflow Rate $(E O R)$ :

$$
E I R_{a g k s t}=A R_{a g k s t}-J C R_{a g k s t}
$$

and

$$
E O R_{\text {agkst }}=S R_{\text {agkst }}-J D R_{\text {agkst }}
$$

where the additive and symmetric growth rate properties of the measure within categories continue to hold. Because of the net job flow identities, EIR agkst $\equiv E O R_{\text {agkst }}$. We only report results for $E I R_{a g k s t}$, which because of the identities always equals $\frac{1}{2} E R R_{a g k s t}$, however its 
statistical precision and other summaries differ from those of $E R R_{\text {agkst }}$ because the identities are only enforced exactly in the micro-data. Weighting, rounding and confidentiality protection procedures can cause the identities to hold only approximately in the public-use data (Abowd et al., 2006).

\subsection{Aggregates and Sub-aggregates}

Great care must be taken when constructing aggregates related to integrated demographic and economic measures of gross labor market flows. As noted in section 2, gross worker flows can be linearly aggregated both within and between establishments because the concept can be consistently defined for the individual, establishment and job. However, gross job flows among demographic categories do not aggregate within establishments because the concepts of job creation and destruction cannot be defined for the individualthese concepts only make sense when defined at the establishment level. An establishment may create one job for a man age 55 and destroy a job for a man age 35 without creating a job at the establishment level. Such creations and destructions within the establishment's demographic employment profile must be defined this way in the Quarterly Workforce Indicators in order to have any coherence associated with the age and gender categories in the gross job creation and destruction statistics. Similarly, the quarterly job and excess reallocation rates cannot be aggregated directly into annual measures because an establishment might create a job in $Q 2$ and destroy a job in $Q 3$, which would produce movement in the quarterly job and excess reallocation rates, but would produce no movement in a $Q 1$ to $Q 1$ annual rate defined across consecutive years. The fact that quarterly gross job reallocation rates cannot be aggregated to annual gross job reallocation rates is well-known-exactly the same reasoning implies that at any level of aggregation, including national, state and industry, the demographic components of the job reallocation rate and the excess reallocation rates will not aggregate linearly. All other components do aggregate in the natural manner. The worker reallocation rates aggregate naturally across all categories, including the demographic and temporal indices.

The national worker reallocation rate for a given demographic group is constructed directly from the appropriate aggregate components

$$
\begin{aligned}
W R R_{a g t} & =\frac{A_{a g t}+S_{a g t}}{\left(B_{a g t}+E_{a g t}\right) / 2} \\
& =\frac{1}{\left(B_{a g}+E_{a g t}\right) / 2} \sum_{k, s}\left(\frac{\left(B_{a g k s t}+E_{a g k s t}\right)}{2} W R R_{a g k s t}\right)
\end{aligned}
$$

where the elimination of a subscript means that the variable was summed over that index. ${ }^{13}$ We note that our definition of the national WRR equals the weighted average of the state and industry component growth rates. The national job reallocation rate for a given demographic group, $J R R_{\text {agt }}$, is similarly defined as

$$
\begin{aligned}
J R R_{a g t} & =\frac{J C_{a g g}+J D_{a g t}}{\left(B_{a g t}+E_{a g t}\right) / 2} \\
& =\frac{1}{\left(B_{a g t}+E_{a g t}\right) / 2} \sum_{k, s}\left(\frac{\left(B_{a g k s t}+E_{a g k s t}\right)}{2} J R R_{a g k s t}\right) .
\end{aligned}
$$

\footnotetext{
${ }^{13}$ In contingency table analysis, replacing the subscript with a + sign indicates the operation of computing the marginal table with respect to the index so replaced. For time series analysis, as we do here, such notation is cumbersome because the time subscipt legitimately uses the + operation. In the notation used here, the letter used in the subscript indicates the variables used to form the relevant marginal table.
} 
Finally, the national excess reallocation rate is simply the difference between the worker and job reallocation rates, $E R R_{\text {agt }}=W R R_{\text {agt }}-J R R_{\text {agt }}$. The national gross inflow and outflow rates are defined with coherent definitions not shown here. We note that national industryspecific gross worker, job, and excess reallocation rates can be defined analogously by aggregating over only the state index.

\subsection{QCEW and BED Variables}

We next define the gross job creation and destruction rates from the BLS sources. We use notation comparable to the notation used for the QWI-based measures to promote clarity in our comparisons. Variables from both the QCEW and BED must be used to create gross job reallocation rates. The BLS computes gross worker and excess reallocation rates by combining data from the QCEW/BED and JOLTS (Boon, Carson, Faberman, and Ilg, 2008). Hence, the integration occurs at the aggregate category level, and not at the establishment level. Furthermore, the JOLTS data exclude establishment births and deaths, which results in a downward bias in the associated WRR and ERR (Davis, Faberman, Haltiwanger, and Rucker, forthcoming). There are no demographic detail in the BED data; however, to facilitate notational clarity we have carried along the age and gender indices, setting them at the appropriate values for overall comparisons. From the QCEW we use:

$Q C E W B_{k s t}=$ beginning-of-quarter employment (BED definition): month-3 employment from the previous quarter $(t-1)$ for all age and gender groups in industry $k$ and state $s$

$Q C E W E_{k s t}=$ end-of-quarter employment (BED definition): month-3 employment from the current quarter $(t)$ for comparable values of the indices.

From the BED we use:

$B E D J C_{k s t}=$ job creations using the establishment change in employment from month-3 of quarter $(t-1)$ to month-3 of quarter $t$ for all age and gender groups in industry $k$ and state $s$

$B E D J D_{k s t}=$ job destructions using the establishment change in employment from month-3 of quarter $(t-1)$ to month-3 of quarter $t$ for all age and gender groups in industry $k$ and state $s$

Because the BED data are constructed from the BLS's longitudinally integrated QCEW (LDB), the employment totals for the beginning and ending quarter employment defined above are fully consistent with the BED definitions of gross job creations and destructions. We define the gross job reallocation rate from the $B E D, B E D J R R$ :

$$
B E D J R R_{k s t}=\frac{B E D J C_{k s t}+B E D J D_{k s t}}{\left(Q C E W B_{k s t}+Q C E W E_{k s t}\right) / 2}
$$

The BLS does not publish $B E D J C_{k s t}$ and $B E D J D_{k s t}$ in fully saturated form. From the published data, we are able to construct the national rate $B E D J R R_{t}$, the state rates $B E D J R R_{s t}$ and an aggregated subset of the national NAICS sector rates $B E D J R R_{k t}$. We also constructed separate gross job creation and job destruction rates on these same bases.

3.5.1. JOLTS Variables-We use only the national JOLTS data. The JOLTS-based worker reallocation rates are defined as:

$$
\begin{aligned}
& \operatorname{JOLTSA}_{t}=\text { total new hires nationally summed across all three months of quarter } t \\
& \operatorname{JOLTSS}_{t}=\text { total separations nationally summed across all three months of quarter } t
\end{aligned}
$$


For compatibility with our comparisons to QWI- and QCEW-based reallocation rates, we define the JOLTS-based worker reallocation rate, JOLTSWRR:

$$
J O L T S W R R_{t}=\frac{J O L T S A_{t}+J O L T S s_{t}}{\left(Q C E W B_{t}+Q C E W E_{t}\right) / 2}
$$

\section{Statistical Methodology}

Two distinct missing data problems must be addressed in order to form potentially reliable national gross worker and job flow measures on a consistent basis. First, a very small amount of the QWI data have been suppressed as a consequence of the publication quality rules applied by the Census Bureau. Reliable imputation of these suppressed items using the confidential micro-data is part of the Bureau's quality improvement plan for the QWI; however, we rely on the published data alone for this paper. Although tedious to implement, we use a reliable monotone missing data imputation system to complete the missing withinstate QWI data. Second, some states still do not participate in the Local Employment Dynamics Federal/State Partnership that is the source of the micro-data from which the QWI are calculated, or have not provided sufficient historical data to create the QWI back to $1993: Q 1$. As we documented in section 2, in the early years, there is a substantial amount of missing QWI data because different states were able to recover historical data for different time periods back to the early 1990s. From $1999: Q 1$ forward, the state-specific missing data represent a small proportion of the working population; hence, we expect that missing data will not matter much during the 2000s. Even though the primary reasons for missing state data are nonparticipation in a voluntary data-provision program, and nonexistence of historical data in the states' archives, nonparticipating state missing data are probably not missing completely at random. We develop a model below that assumes the missing data from nonparticipating states and suppressed items from participating states are ignorable given the published data on those states from the QCEW and the published QWI data (Rubin, 1987). Since the QCEW data are present for essentially all states, NAICS sectors and time periods, they provide the common conditioning information needed to implement this procedure.

\subsection{States with Published QWI Data}

QWI data items are only published when the individual item meets a publication quality standard that depends upon the employment levels and the number of establishments used to compute the indicator. At the state $\times$ NAICS sector $\times$ gender $\times$ age group publication level, a few data items, less than one-tenth of one percent, are not published. We imputed these unpublished numbers using a Multinomial-Dirichlet Posterior Predictive Distribution (PPD) that implements a Bayesian bootstrap procedure (Rubin, 1981). The procedure is identical to the one described below for states that do not have published QWI data. Imputation of missing data arising from the suppressions in the QWI is done before the imputation for states and periods where no QWI data were published. This implements the monotone missing data pattern.

\subsection{States Lacking Published QWI Data}

Because some states are missing early years of QWI data, and because the Census Bureau does not yet publish QWI data for some states, there are missing QWI data that must be imputed. The amount of missing data varies from 70\% of employment in 1993 to $8 \%$ in 2008. The number of states available to serve as complete-data donors for the imputation also varies depending upon the time period considered. There is a trade-off between the number of states with complete data and the start date used for the missing data imputaion 
model. If we use the entire period from $1993: Q 1$ through $2008: Q 4$, only 10 states have complete data. However, from $1999: Q 1$ forward, 37 states have complete data. In order to take advantage of the relative completeness of recent QWI data, we adopt an overlapping sub-sample strategy for the missing data model. Sub-sample $I$ runs from $1993: Q 1$ to 2001 : $Q 4$ and sub-sample II runs from $1999: Q 1$ to $2008: Q 4$. Separate missing data models were developed for each sub-sample using the multiple imputation system described below.

4.2.1. Sub-sample Imputation Models-For each sub-sample, we multiply impute the missing QWI data by sampling 100 implicates from a Multinomial-Dirichlet PPD that assumes the missing data are ignorable (Rubin, 1987) in the rates (not levels) given NAICS sector $\times$ gender $\times$ age group $\times$ time period. We use the same model for the trivial amount of missing data discussed in section 4.1.

For each sub_sample, we prepare the complete-data observations. There are 10 states with complete data in sub-sample I and 37 states with complete QWI data in sub-sample II. ${ }^{14}$ For these states, let

$$
y_{a g s k t}=\left[B_{a g s k t}, E_{a g s k t}, A_{a g s k t}, S_{a g s k t}, J C_{a g s k t}, J D_{a g s k t}\right]
$$

and $\bar{e}_{s k t}=\left(Q C E W B_{s k t}+Q C E W E_{s k t}\right) / 2$. The rates, which we assume to be homogeneous over (agkt) for all states, are defined as a vector

$$
r_{a g s k t}=y_{a g s k t} / \bar{e}_{s k t} \text {. }
$$

Next, we prepare the incomplete-data states. There are 40 and 13 states with incomplete data in sub-samples $I$ and $I I$, respectively. For those states $r_{\text {agskt }}$ is only defined for periods $t$ when the Census Bureau published the QWI data for state $s$; however, $\bar{e}_{s k t}$ is always available from the QCEW data.

To form the Multinomial-Dirichlet PPD for each sub-sample $m$, assume that the prior probability for each complete-data state is equal, $\pi \sim \operatorname{Dir}(\alpha)$ with $\alpha=[1, \ldots, 1]$. Then, for each incomplete-data state, sample $M$ implicates from $M u l t(1, \pi)$, where $M=100$. For a given incomplete-data state $s$ denote the list of Bayesian bootstrap complete-data donor states by $B B_{s}=\left[b b_{s 1}, \ldots b b_{s M}\right]$. Form $M$ completed data samples for state $s$ using the algorithm

$$
\text { if } \begin{aligned}
r_{a g s k t} \text { missing, then } y_{\text {agskt }}^{(\ell, m)} & =r_{a g\left(b b_{s}\right) k t} \times \bar{e}_{s k t} \\
\text { else } y_{\text {agskt }}^{(l, m)} & =r_{\text {agskt }} \times \bar{e}_{s k t} .
\end{aligned}
$$

for $m=I, I I$. This procedure implements a Bayes bootstrap where the candidate records are the complete-data states' rate vectors and the completed data consist of either the published data for state $s$ or imputed data from donor state $b b_{s \ell}$ for implicate $\ell=1, . ., M$ and in each sub-sample $I, I I$.

4.2.2. Combining Sub-samples-Once the implicates were created for each subsample, we combined the two sub-samples using the following weighting system, which

\footnotetext{
${ }^{14}$ We used the QWI vintage available on the Cornell VirtualRDC on October 15, 2009. The District of Columbia was eliminated from the universe for QCEW private employment data because QWI data are not yet available for DC, which has an unusual industry structure that is primarily federal employment.
} 
smooths out any seam in the imputation process over the three-year period in which the subsamples overlap:

$$
w_{t}=\left\{\begin{array}{l}
0 \text { for } t=1993: Q 1-1998: Q 4 \\
w_{t-1}+\frac{1}{13} \text { for } t=1999: Q 1-2001: Q 4 \\
1 \text { for } t=2002: Q 1-2008: Q 4
\end{array}\right.
$$

Then, $y_{\text {agskt }}^{(\ell)}=\left(1-w_{t}\right) y_{\text {agskt }}^{(\ell, I)}+w_{t} y_{\text {agskt }}^{(\ell, I I)}$. The implicates $y_{\text {agskt }}^{(\ell)}$ are constructed in this fashion because the primary differences in data quality between the 1990 s and the 2000 s, as reflected in Figure 1, are due to the inclusion of 30 states beyond the original 18 included in the 2003 initial release of the QWI. Originally, large states were over-represented. States that joined in the mid-2000s were predominately small and medium-sized states. The correlation of state population with the probability of inclusion in the early QWI years cannot be directly controlled, but its influence is reduced by our assumptions of ignorability in the rates and division of the missing data modeling into two sub-samples. Essentially, the over-representation of large states in the published QWI data can only influence our national estimates during the period up to 2001.

\subsection{Summary Statistics}

Once the QWI data have been completed, summary statistics are formed in the usual manner. The worker, job, and excess reallocation rates are aggregated to national level by using the formulae in section 3. Measures of variability and effective missing data rates are computed using the usual Rubin (1987) formulae. We illustrate the calculations here for $W R R_{a g k t}$. All other rates are handled in a comparable way.

The national QWI worker reallocation rate is the average over all states of the implicates:

$$
\overline{W R R}_{\text {agkt }}=\frac{1}{M} \sum_{\ell=1}^{M}\left[\sum_{\forall s} \frac{\left(\frac{B_{\text {agskt }}^{(\ell)}+E_{\text {agskt }}^{(\ell)}}{2}\right) W R R_{\text {agskt }}^{(\ell)}}{\sum_{\forall v}\left(\frac{B_{a g v k t}^{(\ell)}+E_{a g v k t}^{(\ell)}}{2}\right)}\right]
$$

where $W R R_{\text {agskt }}^{(\ell)}, B_{\text {agskt }}^{(\ell)}$, and $E_{\text {agskt }}^{(\ell)}$ are the worker reallocation rate, beginning employment and ending employment, respectively, calculated for implicate $\ell$ in state $s$. The withinimplicate variability is measured by the deviation of $W R R_{\text {agskt }}^{(\ell)}$ from the within-implicate mean

$$
\widehat{W R R}_{a g k t}^{(\ell)}=\sum_{\forall s} \frac{\left(\frac{B_{a g s k t}^{(\ell)}+E_{\text {agskt }}^{(\ell)}}{2}\right) W R R_{\text {agskt }}^{(\ell)}}{\sum_{\forall v}\left(\frac{B_{\text {agvkt }}^{(\ell)}+E_{\text {agvkt }}^{(\ell)}}{2}\right)}
$$

Hence, 


$$
V^{(\ell)}\left[\widehat{W R R}_{a g k t}\right]=\frac{1}{49} \sum_{\forall s} \frac{\left(\frac{B_{a g s k t}^{(\ell)}+E_{a g s k t}^{(\ell)}}{2}\right)\left(W R R_{\text {agskt }}^{(\ell)}-\widehat{W R R}_{\text {agkt }}^{(\ell)}\right)^{2}}{\sum_{\forall v}\left(\frac{B_{\text {agvkt }}^{(\ell)}+E_{\text {agvkt }}^{(\ell)}}{2}\right)} .
$$

where $49=$ number of states -1 . We note that the within-implicate variance of our indicators should, in principle, be calculated from the underlying (confidential) micro-data, but this calculation is not feasible with the public-use data used in this paper. Our within-implicate variance estimator $V^{(\ell)}\left[\widehat{W R R}_{\text {agkt }}\right]$ is almost certainly an over-estimate because the state $\times$ NAICS $\times$ gender $\times$ age group $\times$ time period reallocation rates have been computed from the population of integrated data. They are subject to edit and imputation variability at the micro-data level, which can result in some variability in the published rates that is due to estimation, but not sampling, variability. Although most of the variability in the published rates at the aggregation levels we are using is probably real, it is more conservative to use this estimator for the within-implicate variability than to use zero.

The between-implicate variability is estimated by

$$
B\left[\overline{W R R}_{a g k t}\right]=\frac{1}{M-1} \sum_{\ell=1}^{100}\left(\widehat{W R R}_{a g k t}^{(\ell)}-\overline{W R R}_{a g k t}\right)^{2}
$$

The total variance is estimated by

$$
T\left[\overline{W R R}_{a g k t}\right]=\frac{1}{M} \sum_{\ell=1}^{M} V^{(\ell)}\left[\widehat{W R R}_{a g k t}\right]+\frac{M+1}{M} B\left[\overline{W R R}_{a g k t}\right]
$$

The effective missing data rate is estimated by the ratio of the between-implicate variance to the total variance

$$
\operatorname{MR}\left[\overline{W R R}_{a g k t}\right]=\frac{B\left[\overline{W R R}_{a g k t}\right]}{T\left[\overline{W R R}_{a g k t}\right]}
$$

which equals zero if there are no missing data and one if all the variability is due to missing data. The degrees of freedom for forming confidence intervals around the reallocation rates is estimated by

$$
d f\left[\overline{W R R}_{a g k t}\right]=(M-1)\left(1+\frac{1}{M+1} \frac{\frac{1}{M} \sum_{\ell=1}^{M} V^{(\ell)}\left[\widehat{W R R}_{a g k t}\right]}{B\left[\overline{W R R}_{a g k t}\right]}\right)^{2}
$$

\section{National Quarterly Workforce Indicators}

Table 1 summarizes the national worker and job reallocation rates by age and gender. Over our analysis period, the average worker reallocation rate is $49.0 \%$; the average job 
reallocation rate is $13.0 \%$, and the excess reallocation rate (churning) is the difference between the two, $35.9 \%$. For the national estimates, our standard errors indicate that the first two significant digits are essentially unaffected by estimation uncertainty, especially considering the conservative nature of our within-implicate variance estimator. About $30.2 \%$ and $34.9 \%$ of the estimation uncertainty is due to the incompleteness of the QWI data for the worker and job reallocation rates, respectively. Men and women have essentially identical worker, job and excess reallocation rates. As expected, younger workers experience massively more worker reallocation, and somewhat more job reallocation, leading to much more churning among younger workers.

The data also display distinct seasonal patterns, which as we note later, dominate both the trend and cyclical components of the series. First quarter worker reallocation is substantially lower than the annual average, while third quarter $W R R$ is substantially above average. Over the course of the year, peak to trough seasonal variation in WRR is ten percentage points$25 \%$ of the average rate. By contrast, seasonal variation in the job reallocation rate is only a single percentage point peak to trough, less than $10 \%$ of the average rate. Men and women have essentially the same seasonal variation. Younger workers show seasonal variation in both the $W R R$ and $J R R$ that is about $40 \%$ of the average variation, peak to trough. Prime age WRR and JRR show much less seasonal variation-less than $7 \%$ of the average rate.

Table 2 summarizes the national worker and job reallocation rates by NAICS sector. Once again, the standard errors indicate that the first two significant digits of the reallocation rates are essentially unaffected by estimation error. Industry sectors like Agriculture, Forestry, Fishing, and Hunting (11); Construction (23); Administrative, Support, Waste Management, and Remediation (56); Arts, Entertainment, and Recreation (71); and Accommodation and Food Services (72) display substanially greater than average worker reallocation rates and, for the most part, also display higher job reallocation rates. Utilities (22); Manufacturing (31-33); Finance and Insurance (52); and Management of Companies and Enterprises (55) display substantially lower worker and job reallocation rates than average. It is noteworthy that for most industry sectors the effective missing data rate is comparable to the national average; however, Manufacturing (31-33); Management of Companies and Enterprises (55) and Educational Services (61) all display substantially greater than average effective missing data rates without affecting the reliability of the estimated reallocation rates.

The excess inflow rates and excess reallocation (churning) rates are summarized in Tables 3 and 4 by age and gender, and NAICS sector, respectively. Since these statistics can be calculated by subtraction from the results in Tables 1 and 2, the main purpose of these tables is to display the summaries for churning rates directly, and to provide estimation error and effective missing data rates for these statistics. Estimation error, again, does not materially affect the second significant digit. Effective missing data rates are comparable to the basic rates.

Tables 5 and 6 present the national accession and separation rates by age and gender, and by NAICS sector, respectively. Again, estimation uncertainty does not materially affect the second significant digit. Effective missing data rates are comparable to the worker reallocation rates. Tables 7 and 8 report the same statistics for the components of the job reallocation index-the job creation and destruction rates-again, by age and gender, and by NAICS sector, respectively.

Our main results are also summarized graphically in Figures 2 and 3. Figure 2 compares the QWI Worker Reallocation Rate with the WRR estimated from the JOLTS data. The QWI $W R R$ is plotted with its two standard error confidence band. As anticipated, the QWI WRR is greater than the JOLTS estimate, as it turns out almost twice the magnitude. This is probably 
due to the two problems noted by Davis et al. (forthcoming)-namely, the absence of establishment births and deaths from the JOLTS frame, and an underreporting bias that they document for establishments that are experiencing large contractions. The figure also indicates that the private employer worker reallocation rate estimated from the QWI has more seasonal variability (all results are seasonally unadjusted) and a stronger downward trend over the period than the JOLTS estimates. We conclude that the QWI JRR is probably a more comprehensive measure of worker reallocation than its JOLTS cousin.

Figure 3 compares the QWI Job Reallocation Rate with the job reallocation rate estimated from the BED. In contrast to the WRR results, the two Job Reallocation Rates are very similar. The QWI JRR has essentially the same trend as the BED JRR. There is more seasonality, particularly in the second quarter, in the BED JRR, but overall the two series give a strikingly similar report on the rate of job reallocation.

This result is not a consequence of both series using state Unemployment Insurance administrative records to compute their rates. All four components of the two job reallocation rates are estimated from different records in the state UI systems. For the QWI $J R R$, the numerator job creations and destructions are calculated by comparing the number of employees in each demographic group who have UI wage records in quarters $t-1$ and $t$ to those who have wage records in quarters $t$ and $t+1$. For the BED JRR, the numerator job creations and destructions are calculated by comparing the number of persons on payroll as of the $12^{\text {th }}$ calendar day in the month before the quarter begins to the number on payroll as of the $12^{\text {th }}$ calendar day of the last month of the quarter. These two methods of calculating gross job creations and destructions are obviously related, but they are by no means constrained to be similar. As well as the numerators, the denominators of these job reallocation rates are estimated using different administrative records. The QWI average employment over the quarter is the average of the number of persons with UI wage records in quarters $t-1$ and $t$ with the number who have wage records in quarters $t$ and $t+1$. The BED average employment comes directly from the QCEW and is the average of employment on the $12^{\text {th }}$ calendar date in the last month of the previous quarter with the employment on the $12^{\text {th }}$ calendar date of the last month of the current quarter. The QWI use the QCEW month-1 employment as a benchmark for creating the final weight used to aggregate the micro-data into the published series (Abowd et al., 2009); however the month-3 employment is never used. Given the closeness of the levels of these two series and the similarity in their seasonal patterns, we conclude that both series are measuring essentially the same underlying job reallocation rate. This gives us additional confidence in the QWI measures when we use them to estimate job reallocation rates for demographic and industry sub-groups not published or estimable in the BED series.

Figure 4 confirms the similarity of national worker, job and excess reallocation rates for men and women. The figure shows that the level, trend, and seasonality of these reallocation rates do not differ by gender. All series are within estimation error of the overall series and the series for the other gender, which can be confirmed by examining Tables 1 and 3.

Figure 5 provides a striking visual description of the age-related heterogeneity in national excess reallocation (churning) rates. The rates are nearly monotonic in age with 14-18 yearolds displaying the greatest churning rate, and the most seasonal variability and 55-64 yearolds displaying the least. The national average excess reallocation rate and the rate for 25-34 year-olds are essentially coincident. Figure 6 shows that the heterogeneity in age-specific excess reallocation rates is exacerbated by industrial sector variation with Agriculture, Forestry, Fishing, and Hunting (11); Administrative, Support, Waste Management, Remediation (56); and Educational Services (61) dominating the age-related heterogeneity in churning rates. 


\section{Conclusions}

Using similar data for the 1990s and a single state (Maryland), Burgess, Lane, and Stevens (2000) estimated that the excess reallocation rate (churning) for manufacturing was $11 \%$ while that of nonmanufacturing sectors was $19 \%$. Using national data for the period from 1993 : $Q 1$ through $2008: Q 3$., our estimated excess reallocation rate for manufacturing is $17 \%$ while the overall rate is $36 \%$. Nationally representative data thus indicate that overall churning is considerably greater than those authors estimated. However, they also estimated that excess reallocation rates were over $70 \%$ of worker reallocation rates in nonmanufacturing and $46 \%$ of worker reallocation rates in manufacturing. The nonmanufacturing estimate holds up pretty well in nationally representative data. We estimate that the excess reallocation rate (churning) is $73 \%$ of the worker reallocation rate nationally over our time period, and not dominated by a trend. In manufacturing, churning is $67 \%$ of the worker reallocation rate, which is not as different from nonmanufacturing as they found for the state of Maryland.

The only other attempts to estimate national worker reallocation rates, Davis, Faberman, and Haltiwanger (2006); Boon, Carson, Faberman, and Ilg (2008), appear to suffer from a serious underestimation bias due to the design of the JOLTS sampling frame and nonrepresentativeness of the reports of large establishments, as described in Davis, Faberman, Haltiwanger, and Rucker (forthcoming). We document the magnitude of this bias by showing that our nationally representative worker reallocation rate is, at $49 \%$, more than double the $19 \%$ quarterly rate estimated by Davis et al. (2006). Given the demonstrated similarity between our job reallocation rates and those estimated from the BED when they can be compared, it seems reasonable to conclude that our worker reallocation rates, based on the same QWI data as our job reallocation rates, are more representative of the overall private economy than the JOLTS estimates.

As already noted, the national job reallocation rate based on QWI inputs shows similar level, trend, and seasonality to the job reallocation rate based on the BED as described in Spletzer, Faberman, Sadeghi, Talan, and Clayton (2004) and Davis, Faberman, and Haltiwanger (2006). The demonstrated contribution from estimating job reallocation rates from the QWI is that they are accurate enough to permit estimation at the national NAICS sector $\times$ age $\times$ gender level, thus permitting estimation and forecasting, for the first time, of the interaction between the demographic characteristics and industrial sector. Our figures indicate that job and excess reallocation rates are not very different by gender but, as anticipated, vary enormously by age group, and by age group across industrial sectors.

We have created national gross worker and job flow statistics for the period from $1993: Q 1$ through $2008: Q 3$, characterizing worker flows by the worker reallocation rate and job flows by the job reallocation rate. Our methods demonstrate that the Census Bureau's Quarterly Workforce Indicators can reliably estimate these rates to two significant digits at the national level. Fully saturated estimates by NAICS sector, gender and age group were produced. The incompleteness of the QWI data, which arises from the fact that different states joined the LED Federal/State Partnership at different dates and with historical data of different longevity, does not materially affect the quality of the national QWI data.

The national estimates from the QWI are an important enhancement to existing series because they include demographic and industry detail for worker and job flows compiled from underlying micro-data that have been consistenly integrated by the Longitudinal Employer-Household Dynamics Program at the Census Bureau. The estimates produced for this paper were compiled exclusively from public-use data series and are available for download. 


\section{Acknowledgments}

This research uses data from the Census Bureau's Longitudinal Employer-Household Dynamics (LEHD) Program, which was partially supported by the following grants: National Science Foundation (NSF) SES-9978093, SES-0339191 and ITR-0427889; National Institute on Aging AG018854; and grants from the Alfred P. Sloan Foundation. Both authors also acknowledge partial direct support by NSF grants CNS-0627680, SES-0820349, SES-0922005, and SES-0922494 and by the Census Bureau.

\section{References}

Abowd JM, Corbel P, Kramarz F. The entry and exit of workers and the growth of employment: An analysis of French establishments. Review of Economics and Statistics. 1999; 81(2):170-187.

Abowd JM, Haltiwanger JC, Lane JI. Integrated Longitudinal Employee-Employer Data for the United States. American Economic Review. 2004; 94(2):224-229.

Abowd, JM.; Stephens, BE.; Vilhuber, L. Technical Paper TP-2006-02, LEHD. U.S. Census Bureau; 2006. Confidentiality protection in the Census Bureau's Quarterly Workforce Indicators.

Abowd, JM.; Stephens, BE.; Vilhuber, L.; Andersson, F.; McKinney, KL.; Roemer, M.; Woodcock, SD. The LEHD infrastructure files and the creation of the Quarterly Workforce Indicators. In: Dunne, T.; Jensen, JB.; Roberts, MJ., editors. Producer Dynamics: New Evidence from Micro Data. CRIW. University of Chicago Press for the NBER; 2009. p. 149-230.

Abowd JM, Vilhuber L. The sensitivity of economic statistics to coding errors in personal identifiers. Journal of Business and Economic Statistics. 2005; 23(2):133-152.

Abowd JM, Zellner A. Estimating Gross Labor Force Flows. Journal of Business and Economic Statistics. 1985; 3:254-283.

Anderson, P.; Meyer, B. The extent consequences of job turnover. In: Winston, C.; Baily, MN.; Reiss, PC., editors. Brookings Papers in Economic Activity, Microeconomics. The Brookings Institution; 1994. p. 177-249.

Benedetto G, Haltiwanger J, Lane J, McKinney K. Using worker flows in the analysis of the firm. Journal of Business and Economic Statistics. 2007; 25(3):299-313.

Boon Z, Carson CM, Faberman RJ, Ilg RE. Studying the labor market using BLS labor dynamics data. Monthly Labor Review. 2008; 131(2):3-16.

Burgess S, Lane J, Stevens D. Job flows, worker flows, and churning. Journal of Labor Economics. 2000; 18(3):473-502.

Burgess S, Lane J, Stevens D. Churning dynamics: an analysis of hires and separations at the employer level. Labour Economics. 2001; 8:1-14.

Davis, SJ.; Faberman, RJ.; Haltiwanger, JC.; Rucker, I. Adjusted estimates of worker flows and job openings in JOLTS. In: Abraham, K.; Spletzer, J.; Harper, M., editors. Labor in the New Economy. CRIW. University of Chicago Press for the NBER; forthcoming

Davis SJ, Haltiwanger J. Gross job creation and destruction: Microeconomic evidence and macroeconomic implications. NBER Macroeconomics Annual. 1990; 5:123-168.

Davis SJ, Haltiwanger J. Gross job creation, gross job destruction, and employment reallocation. Quarterly Journal of Economics. 1992; 107(3):819-863.

Davis, SJ.; Haltiwanger, JC.; Schuh, S. Job creation and destruction. Cambridge, MA: MIT Press; 1996.

Davis ST, Faberman RJ, Haltiwanger J. The flow approach to labor markets: New data sources and micro-macro links. Journal of Economic Perspectives. 2006; 20(3):3-26.

Dunne T, Roberts MJ, Samuelson L. Plant turnover and gross employment flows in the U.S. manufacturing sector. Journal of Labor Economics. 1989; 7(1):48-71.

Pivetz TR, Searson MA, Spletzer JR. Measuring job and establishment flows with BLS longitudinal microdata. Monthly Labor Review. 2001; 124(4):13-20.

Poterba JM, Summers LH. Reporting errors and labor market dynamics. Econometrica. 1986; 54(6): 1319-1338.

Rubin DB. The Bayesian bootstrap. The Annals of Statistics. 1981; 9:130-134.

Rubin, DB. Multiple Imputation for Nonresponse in Surveys. New York: Wiley; 1987. 
Spletzer JR, Faberman RJ, Sadeghi A, Talan DM, Clayton RL. Business employment dynamics: new data on gross job gains and losses. Monthly Labor Review. 2004; 127:29-42. 


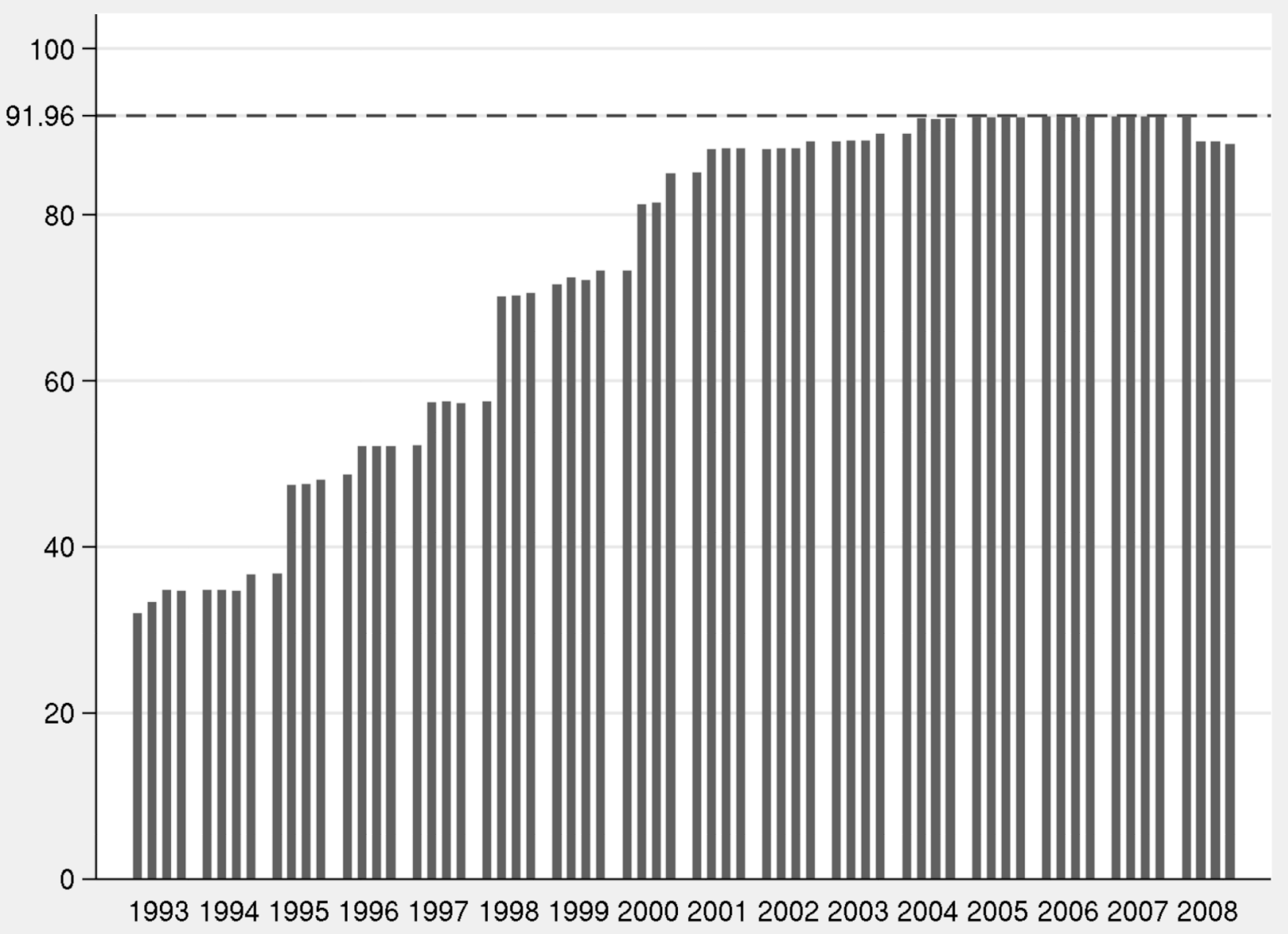

Figure 1.

QWI Data Availability 


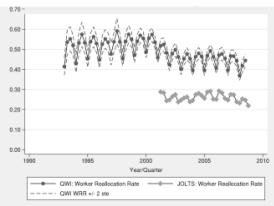

Figure 2.

Comparison of QWI and JOLTS Worker Reallocation Rates 


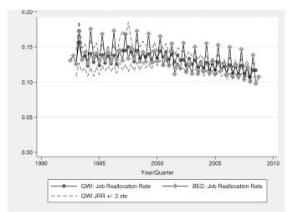

Figure 3.

Comparison of QWI and BED Job Reallocation Rates 


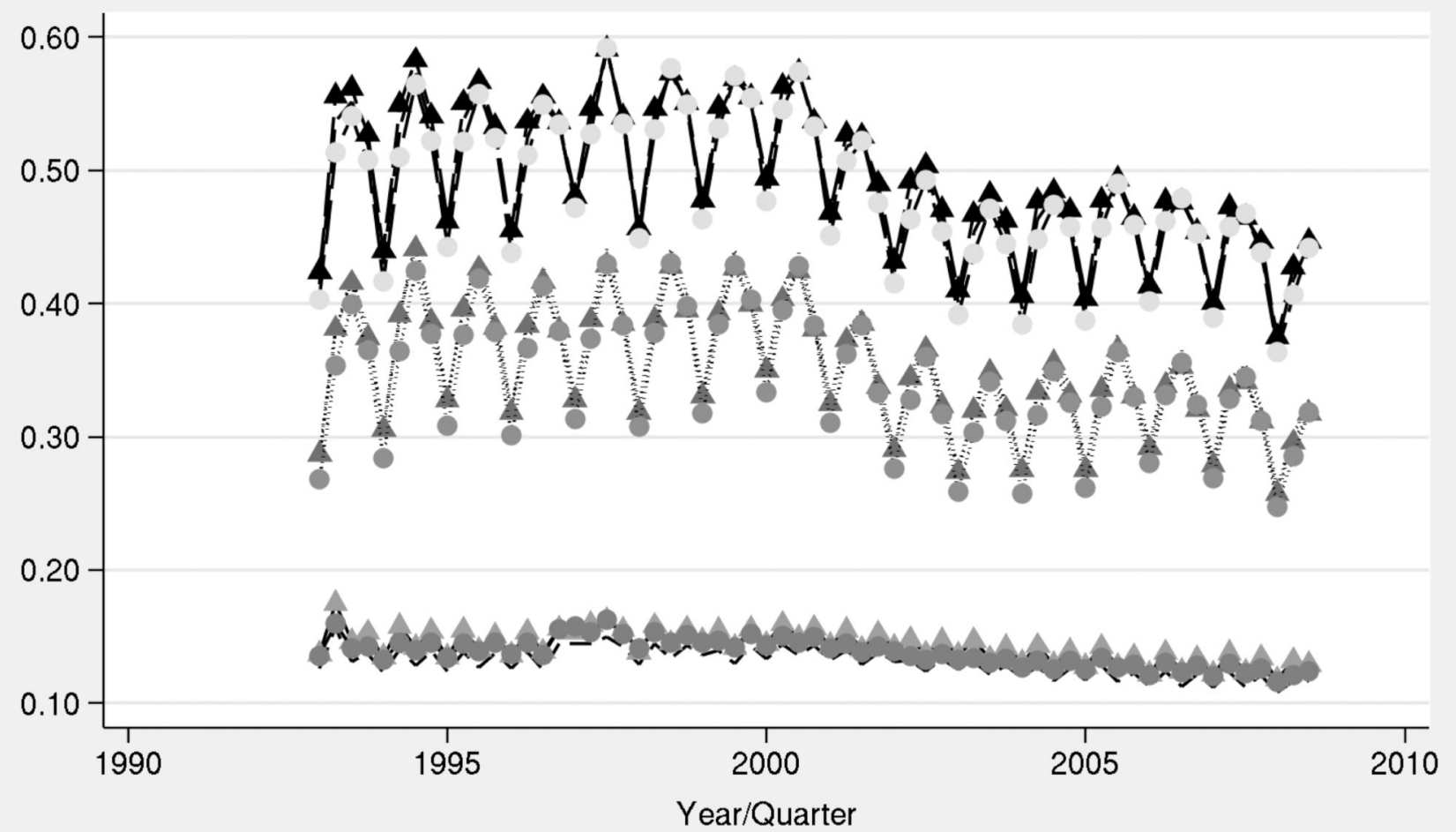

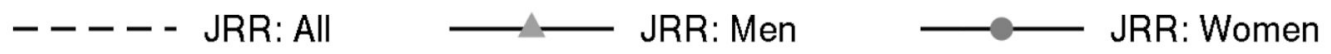

$$
\begin{aligned}
& --- \text { WRR: All } \quad \leftarrow-\text { WRR: Men } \quad--- \text { WRR: Women } \\
& \text { ERR: All ERR: Men …........................... ERR: Women }
\end{aligned}
$$

Figure 4.

QWI Reallocation Rates for Men and Women 

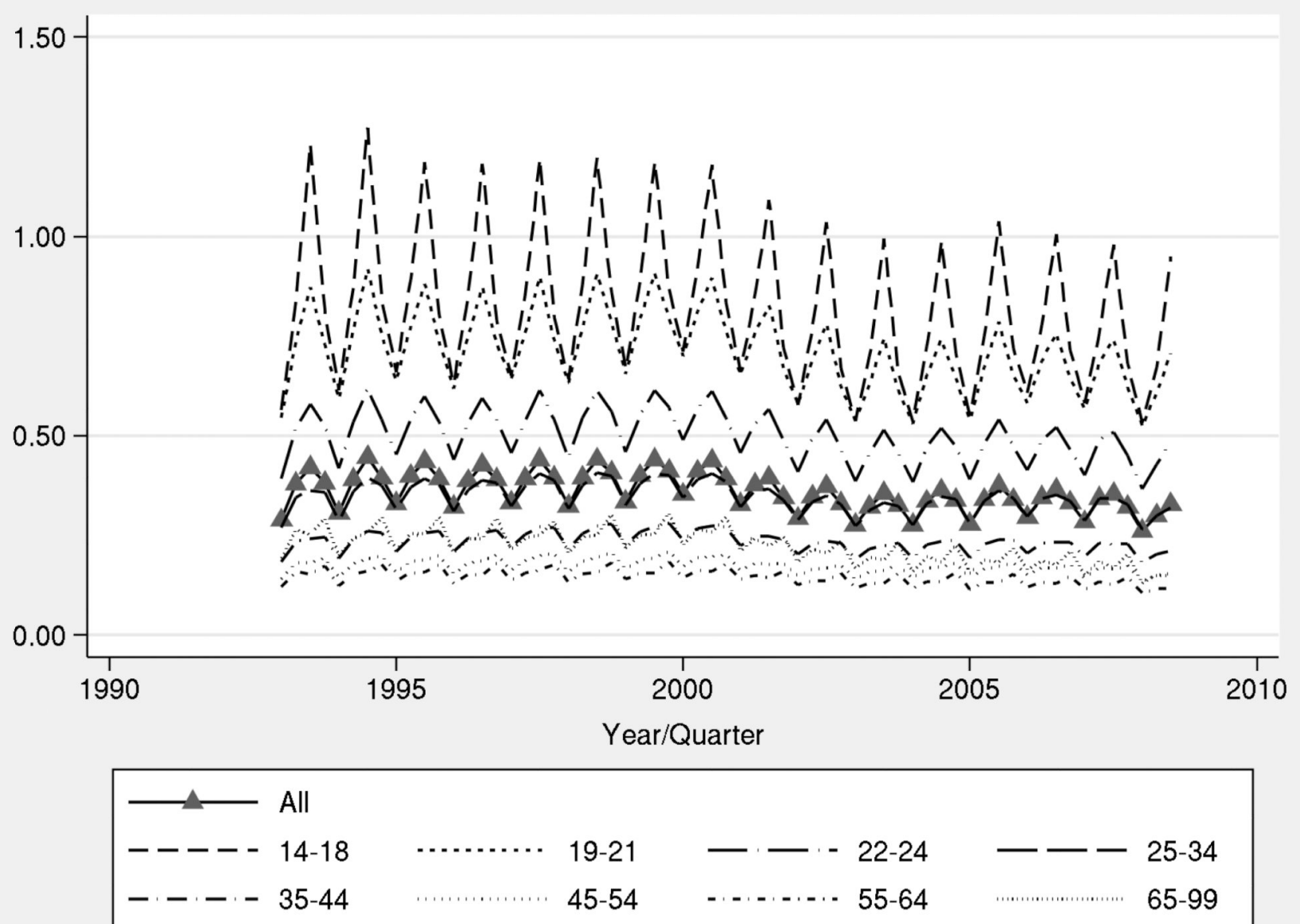

Figure 5.

Excess Reallocation Rates (Churning) by Age Group 


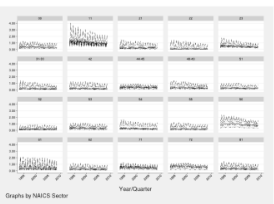

Figure 6.

Excess Reallocation Rates (Churning) by Age Group and NAICS Sectors

Note: NAICS sectors are referenced by their numeric abbreviation, where $00=$ "All NAICS

Sectors", 11 = "Agriculture, Forestry, Fishing, and Hunting", 21 = "Mining, Quarrying, and

Oil and Gas Extraction", 22 = "Utilities", 23 = "Construction", 31-33= "Manufacturing", 42

= "Wholesale Trade", 44-45= "Retail Trade", 48-49= "Transportation and Warehousing", 51 = "Information", 52 = "Finance and Insurance", 53 = "Real Estate and Rental and Leasing“, 54 = "Professional, Scientific, and Technical Services", 55 = "Management of Companies and Enterprises", 56 = "Administrative, Support, Waste Management, Remediation", 61 = "Educational Services", 62 = "Health Care and Social Assistance", $71=$ "Arts, Entertainment, and Recreation", 72 = "Accommodation and Food Services", $81=$ "Other Services (except Public Administration)", 92 = "Public Administration". 


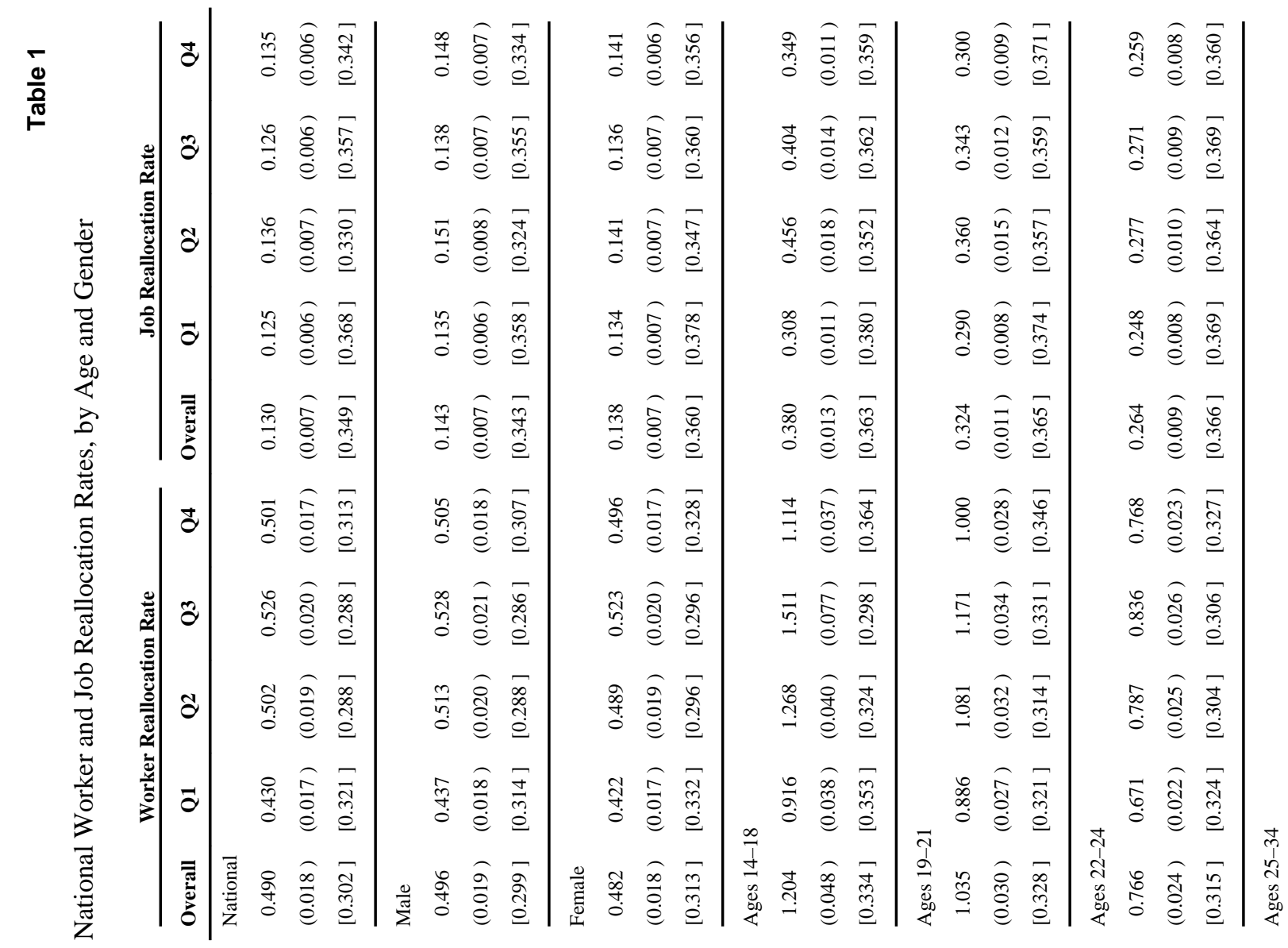




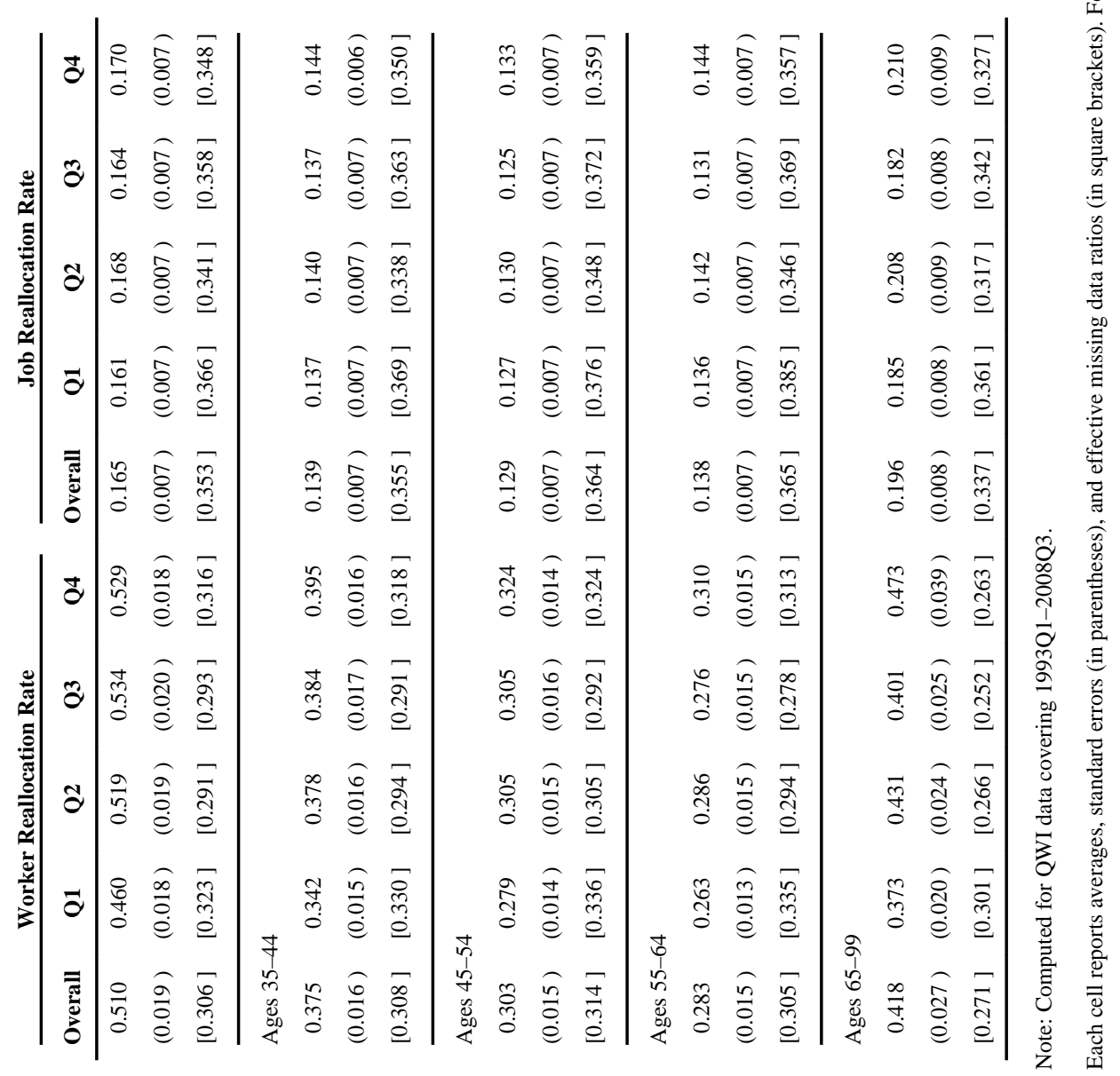




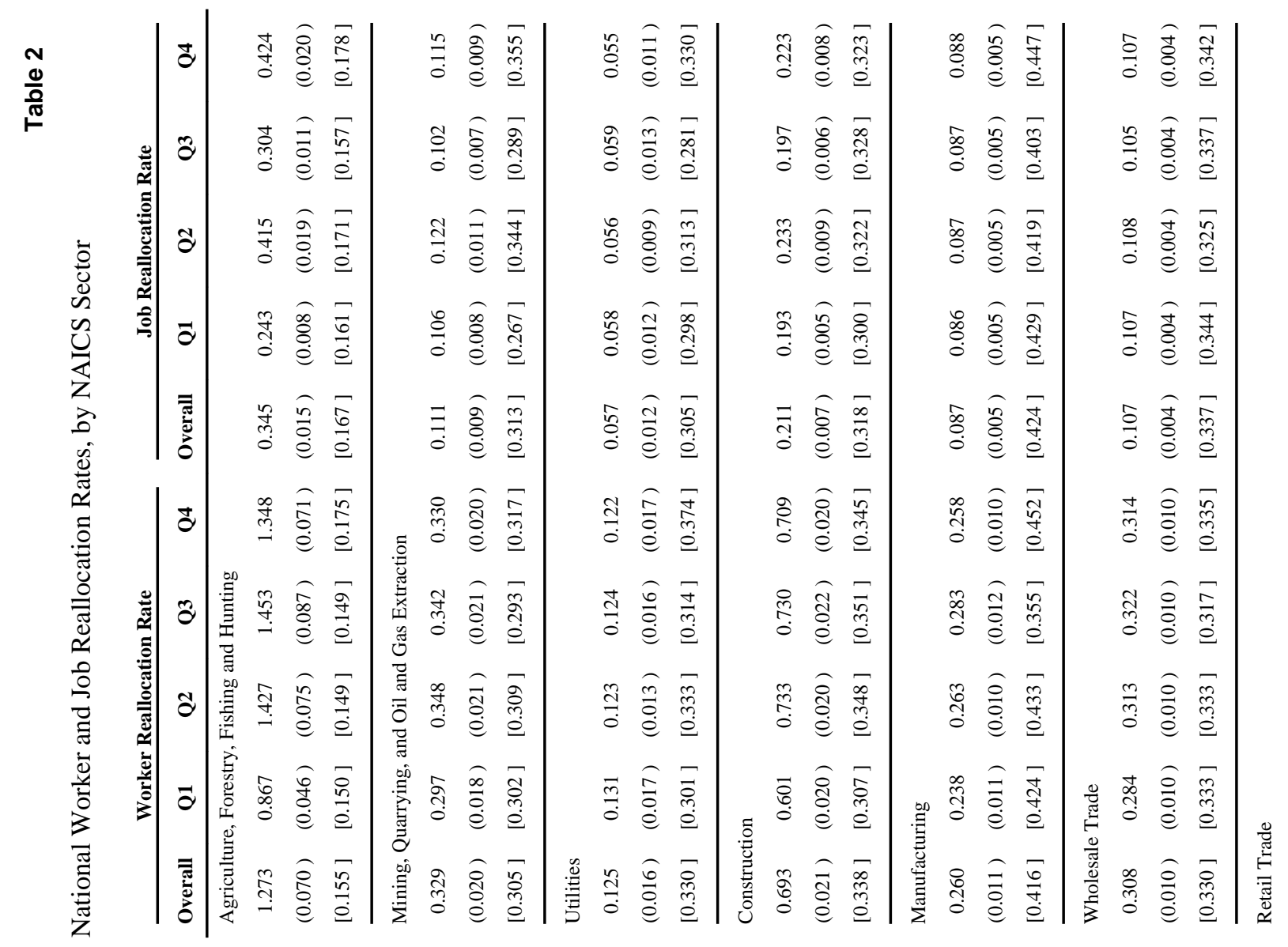




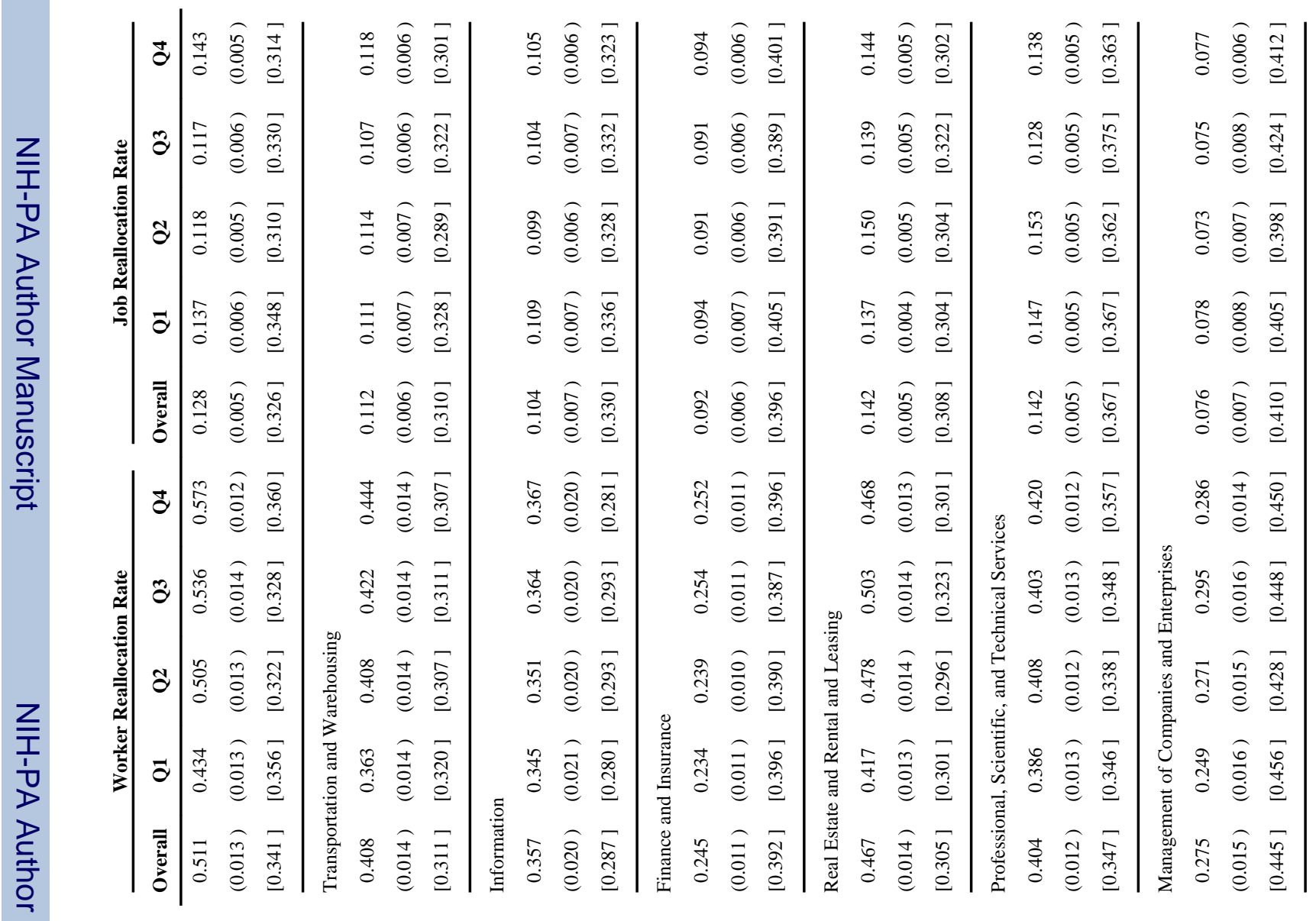




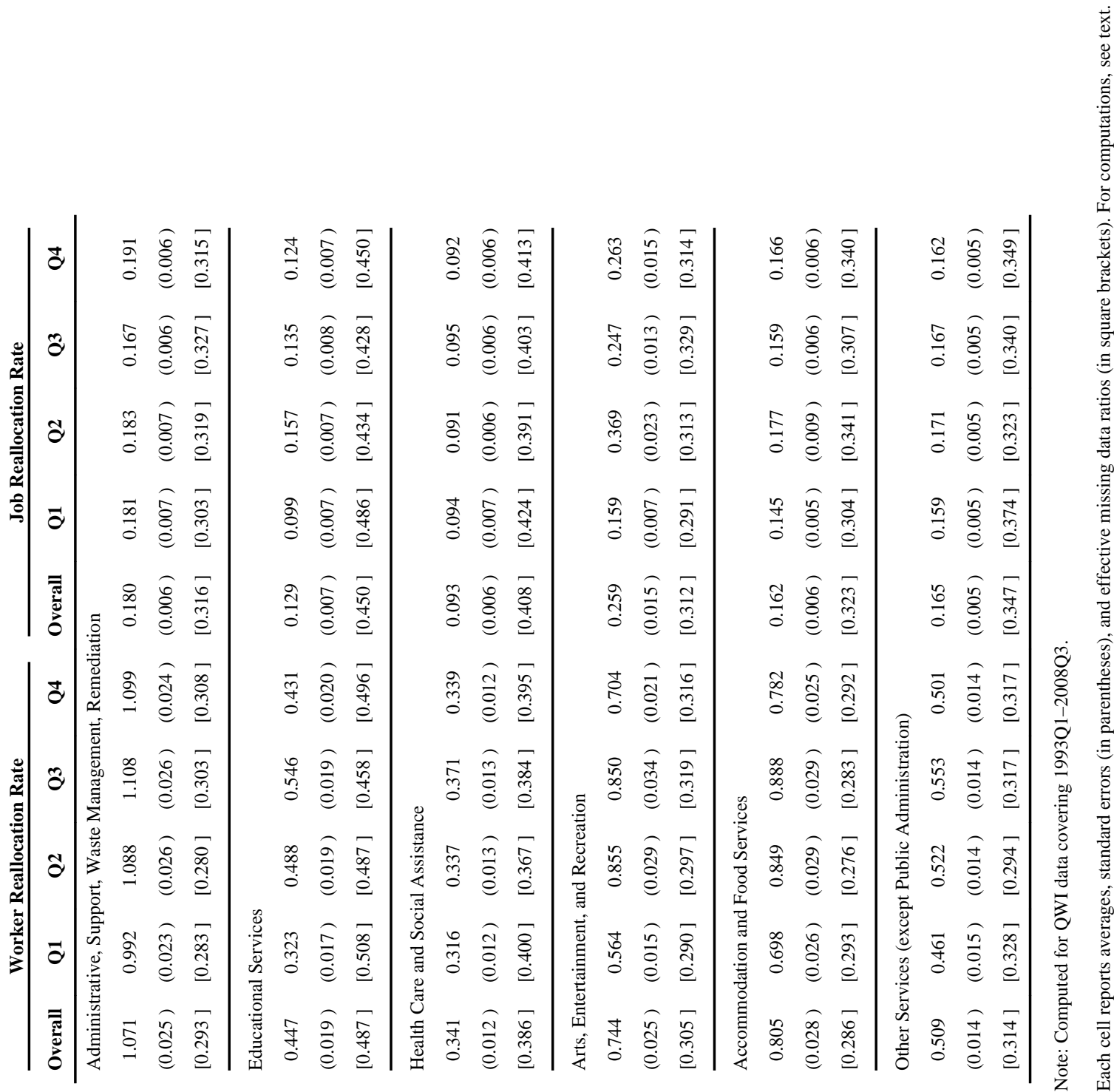




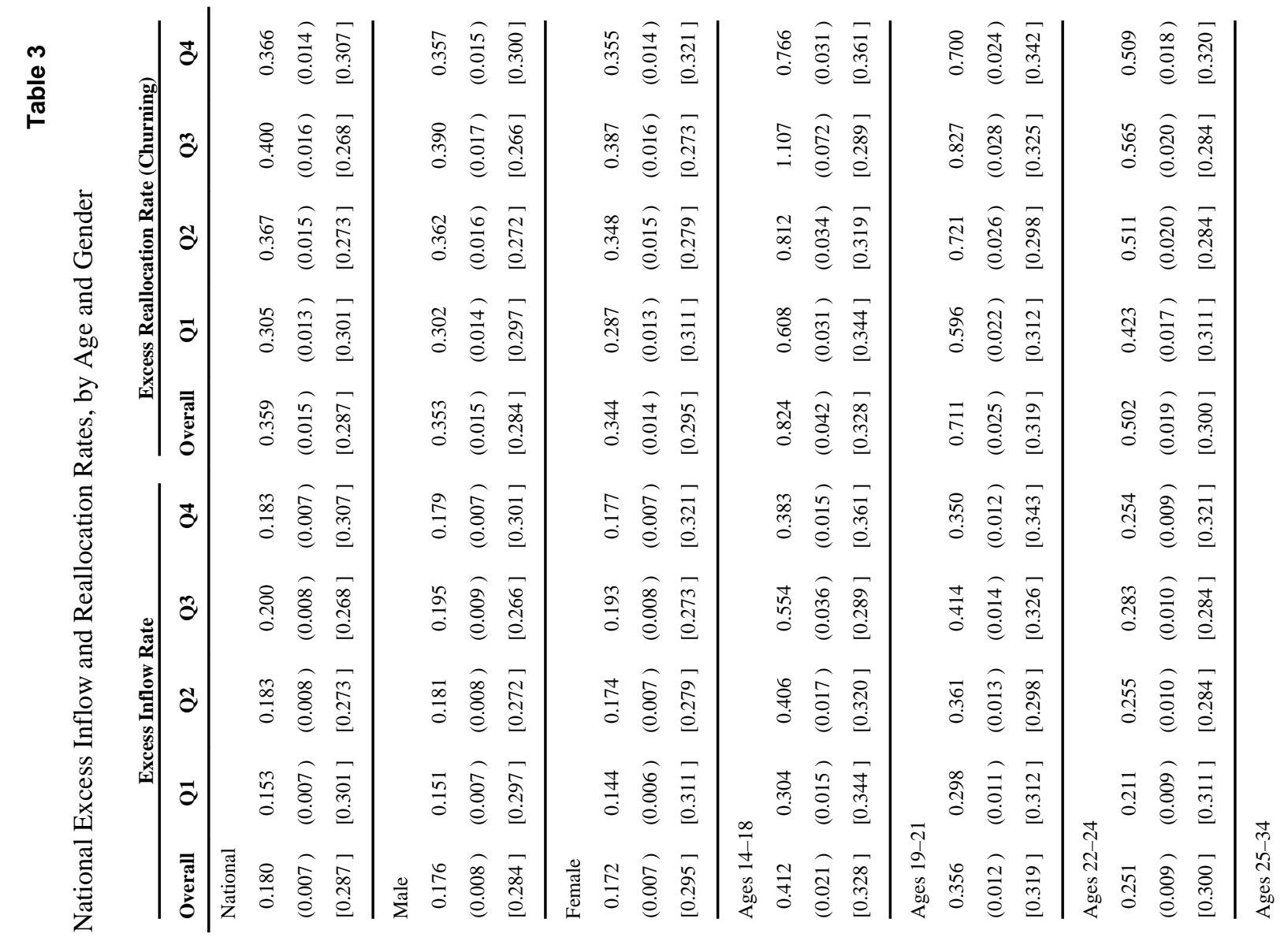




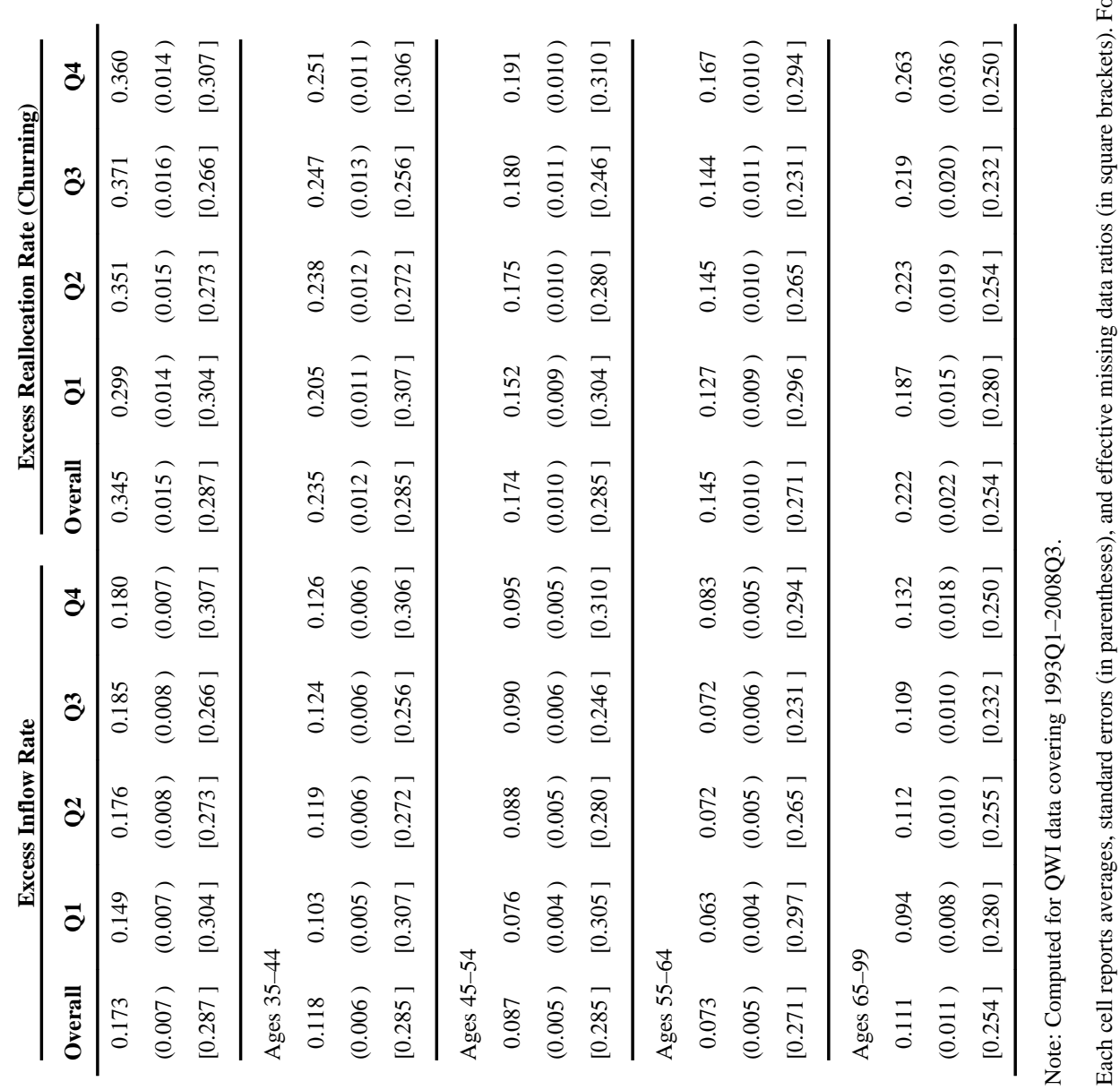




$$
\begin{aligned}
& \stackrel{+}{\frac{0}{0}}
\end{aligned}
$$

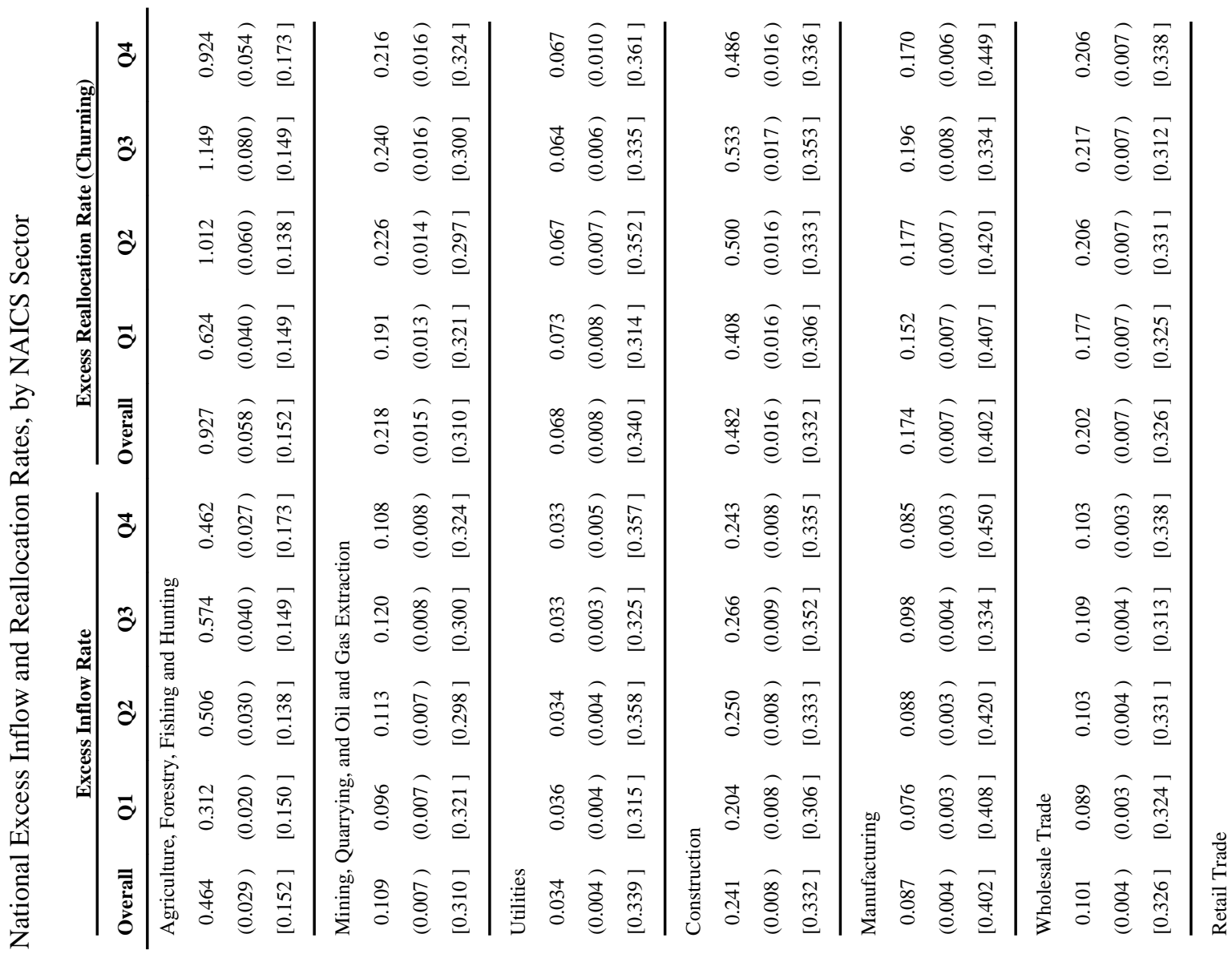




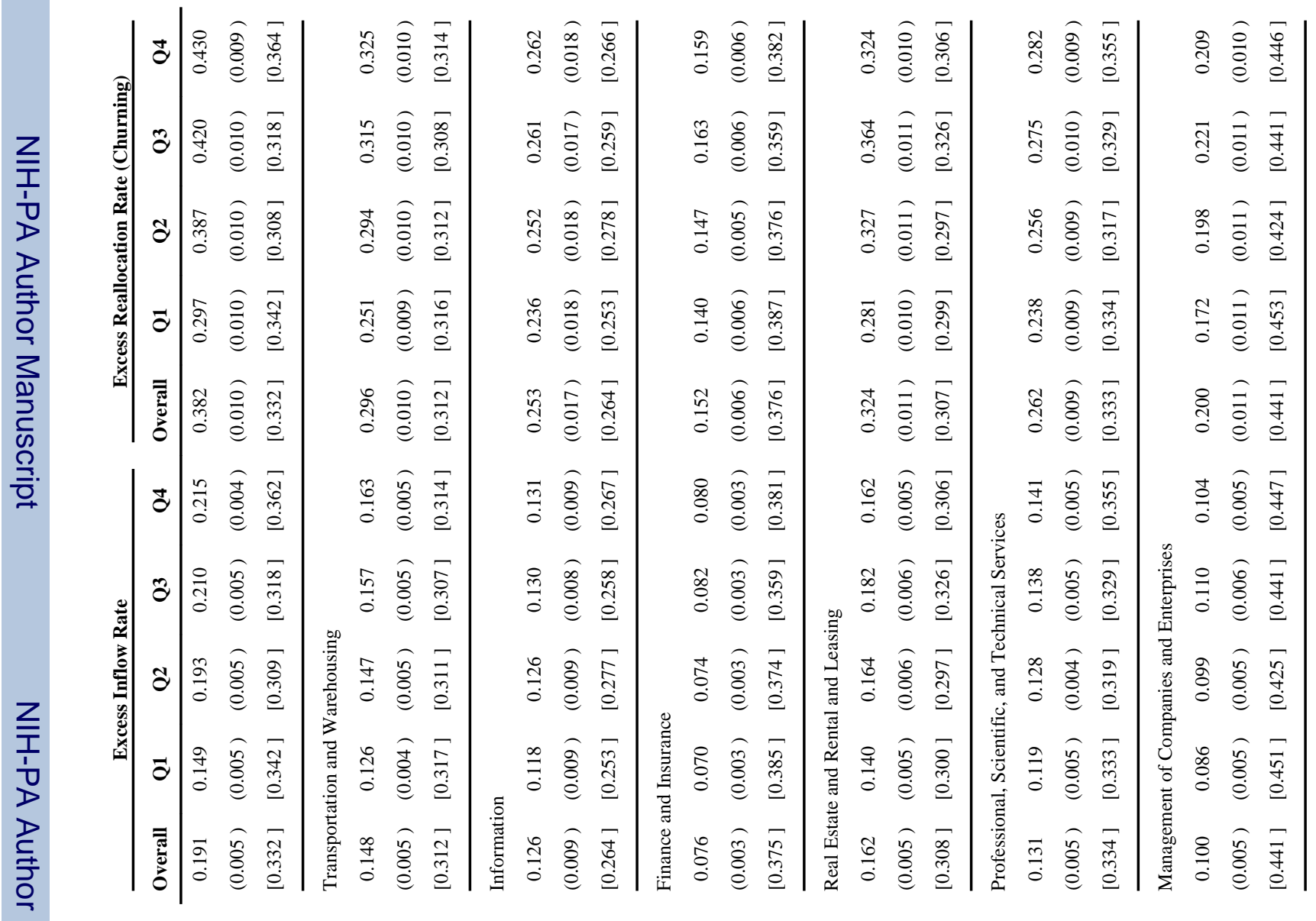




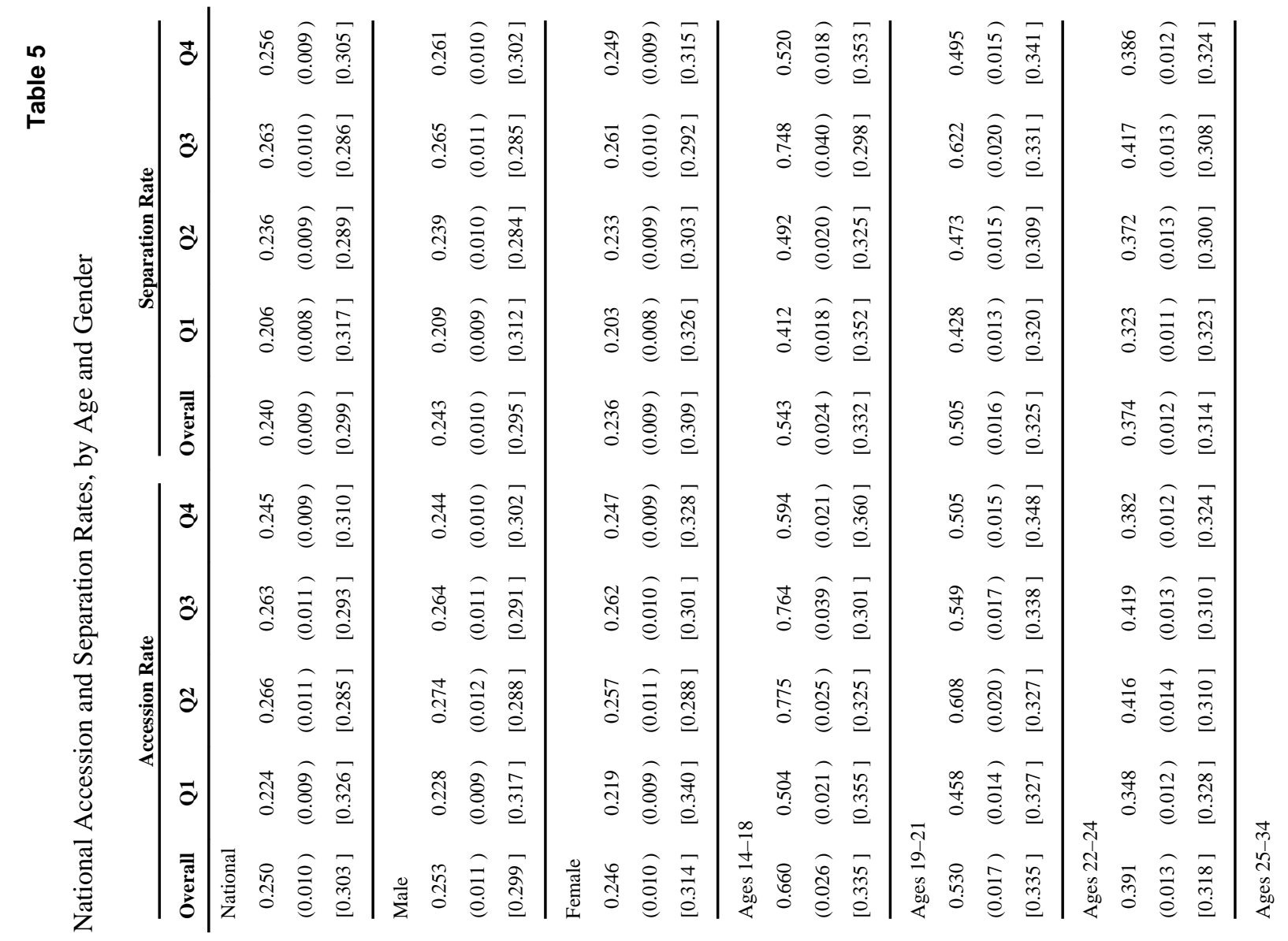




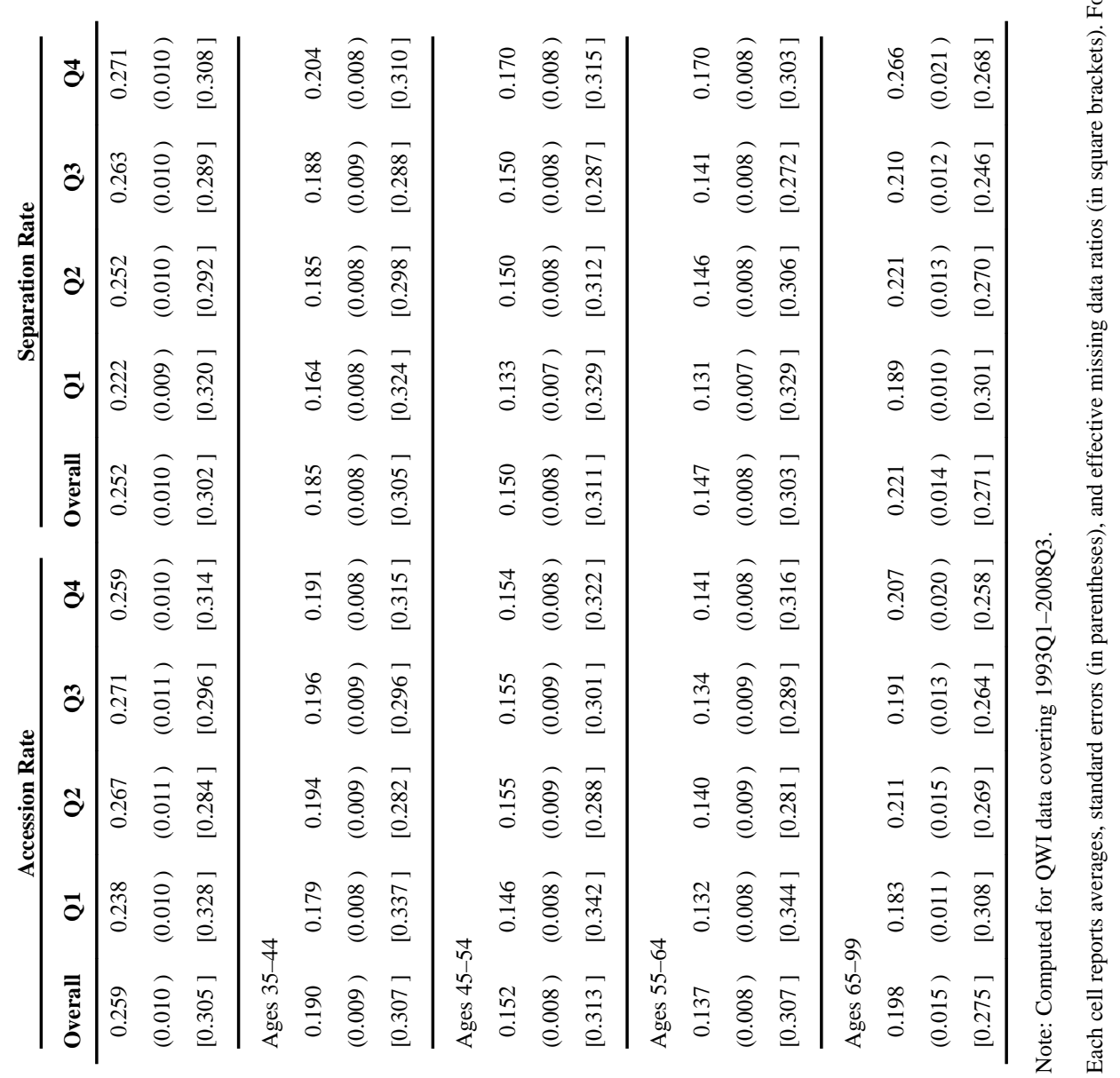




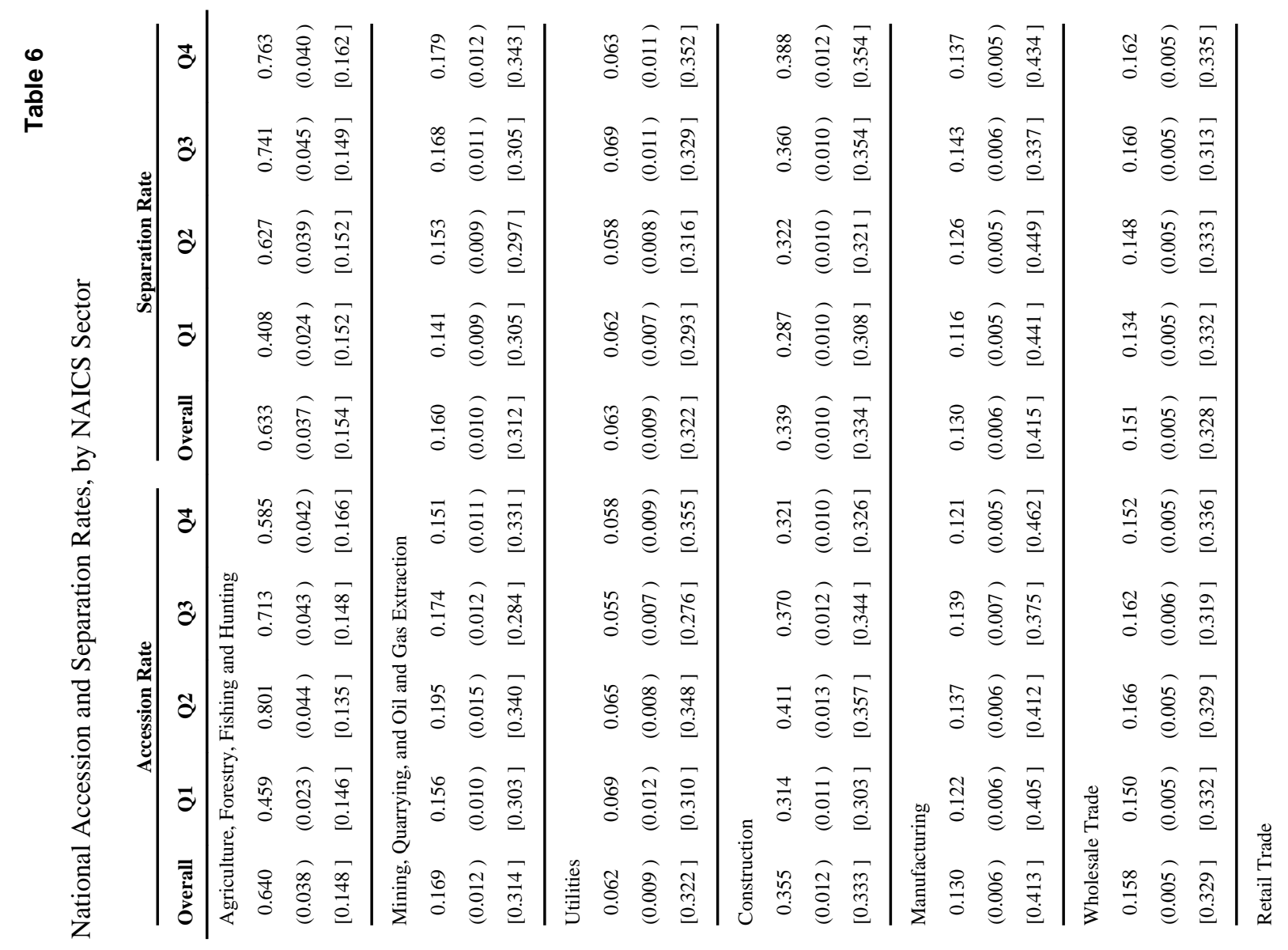




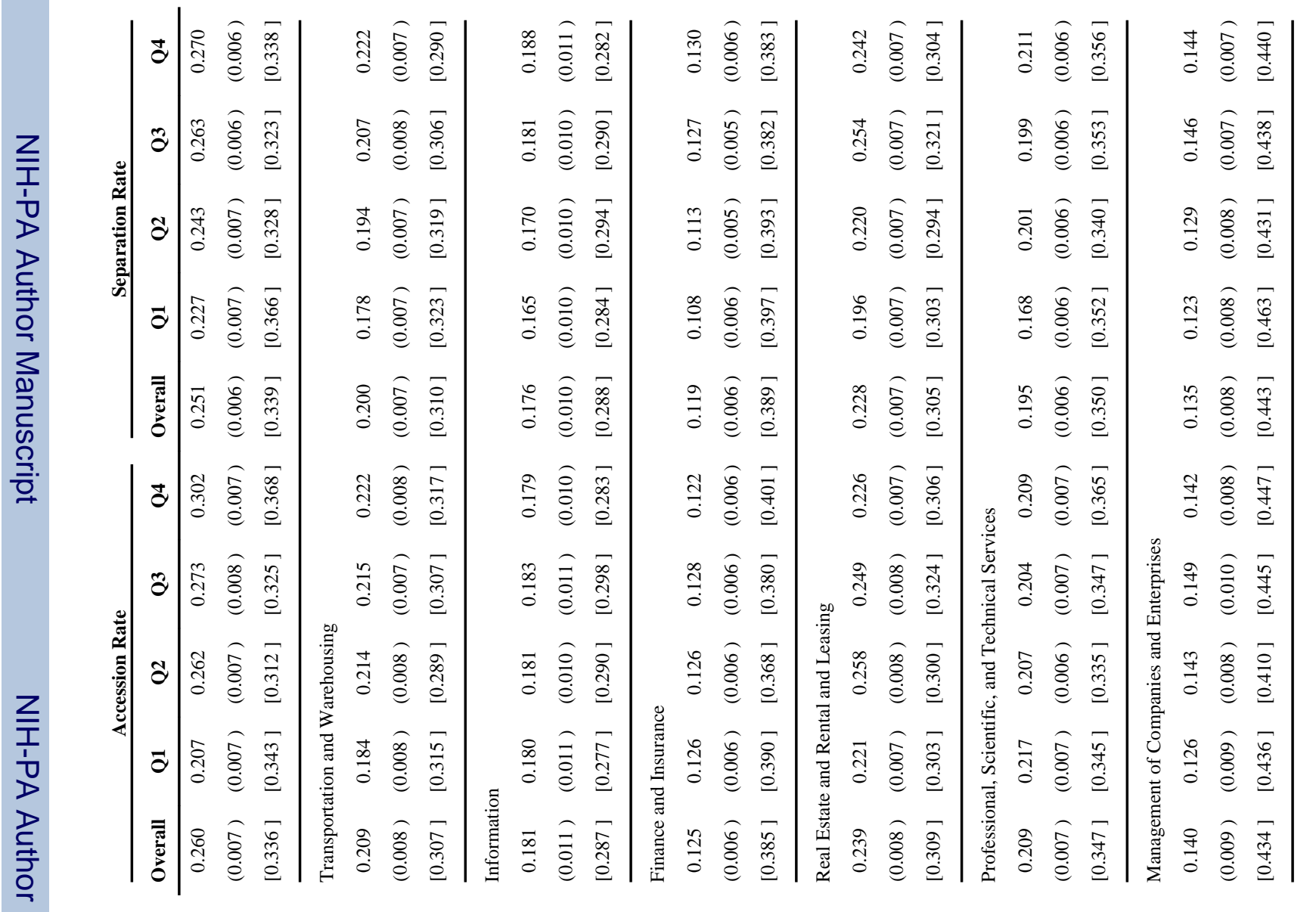




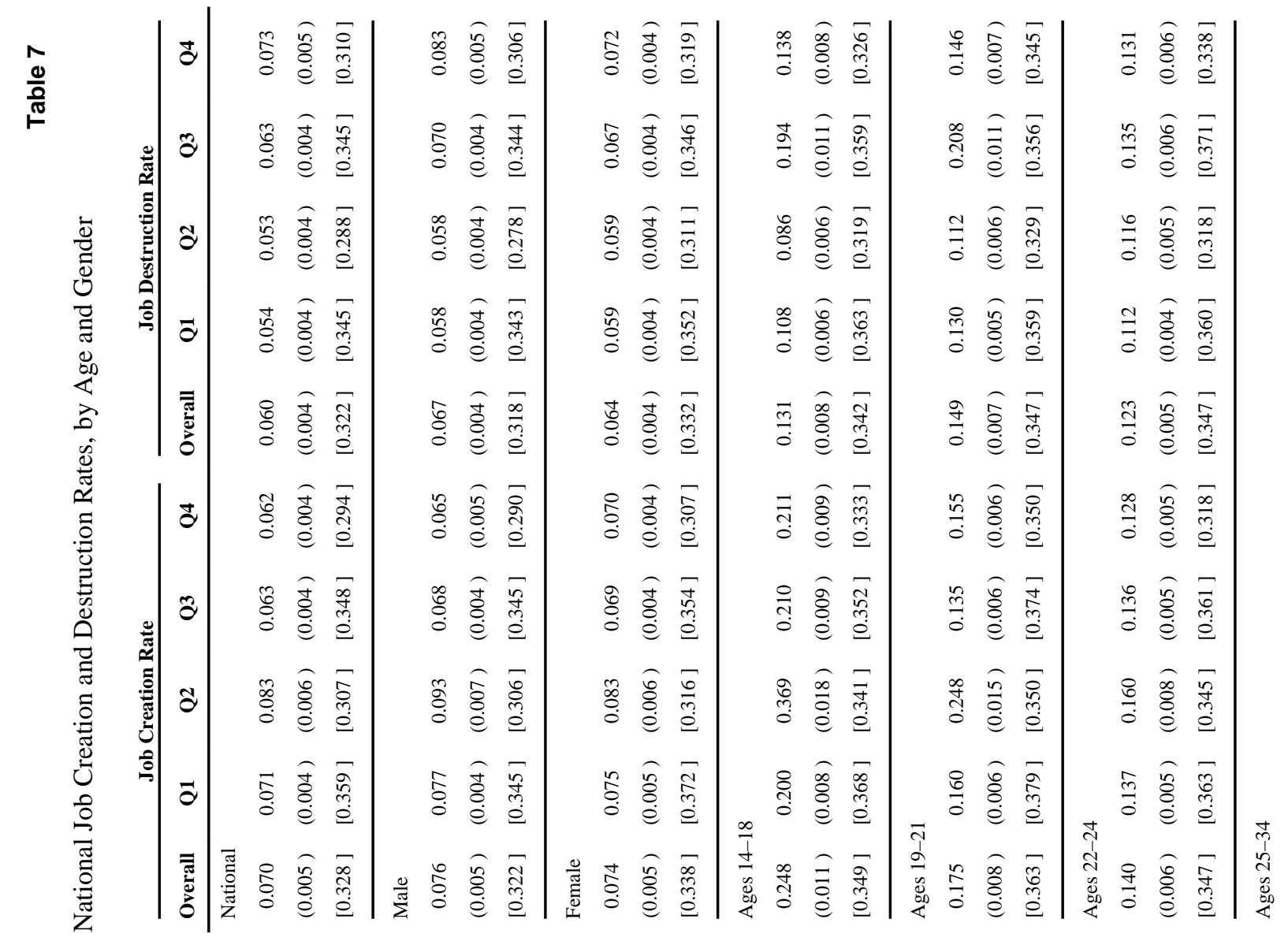




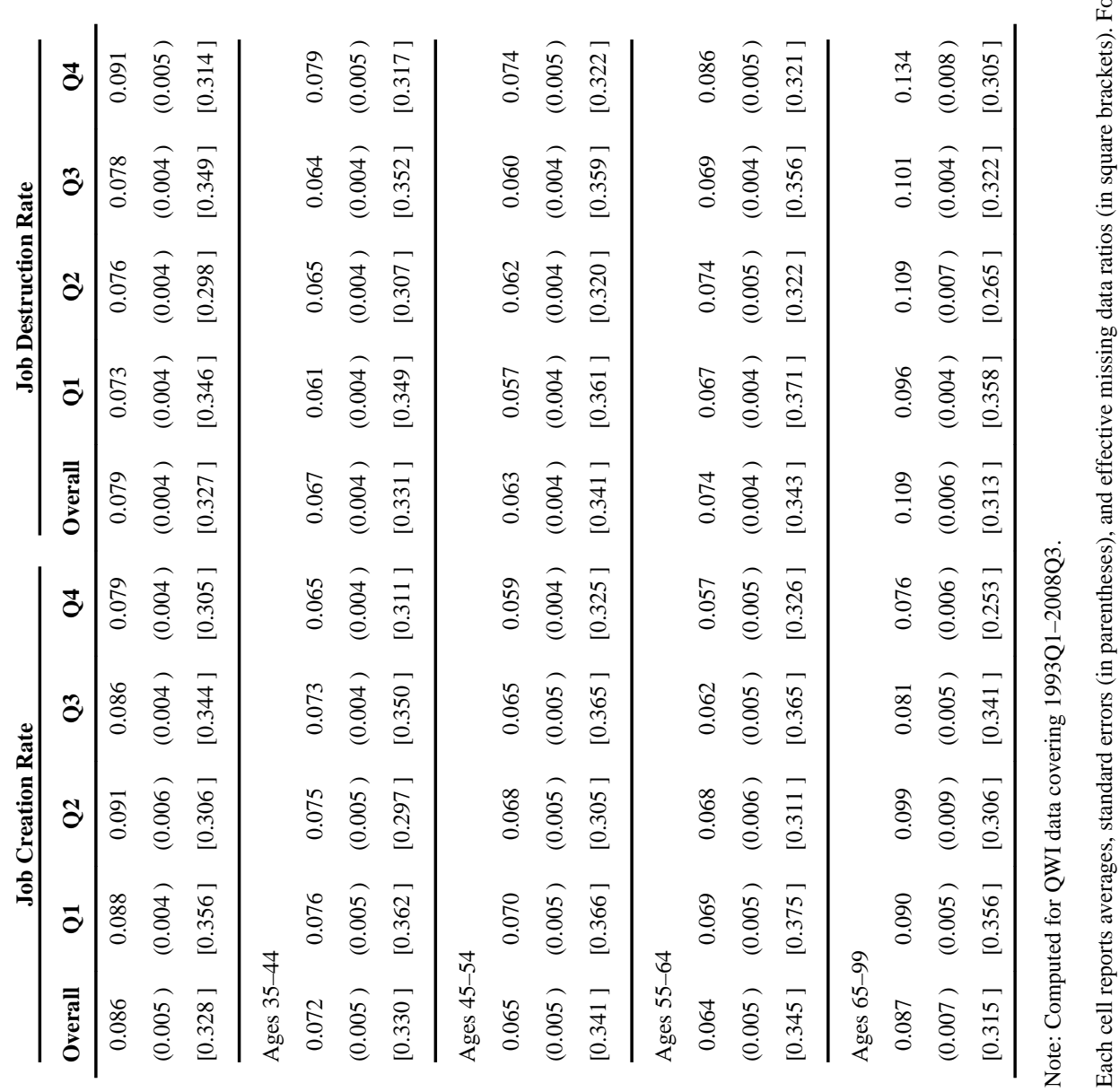




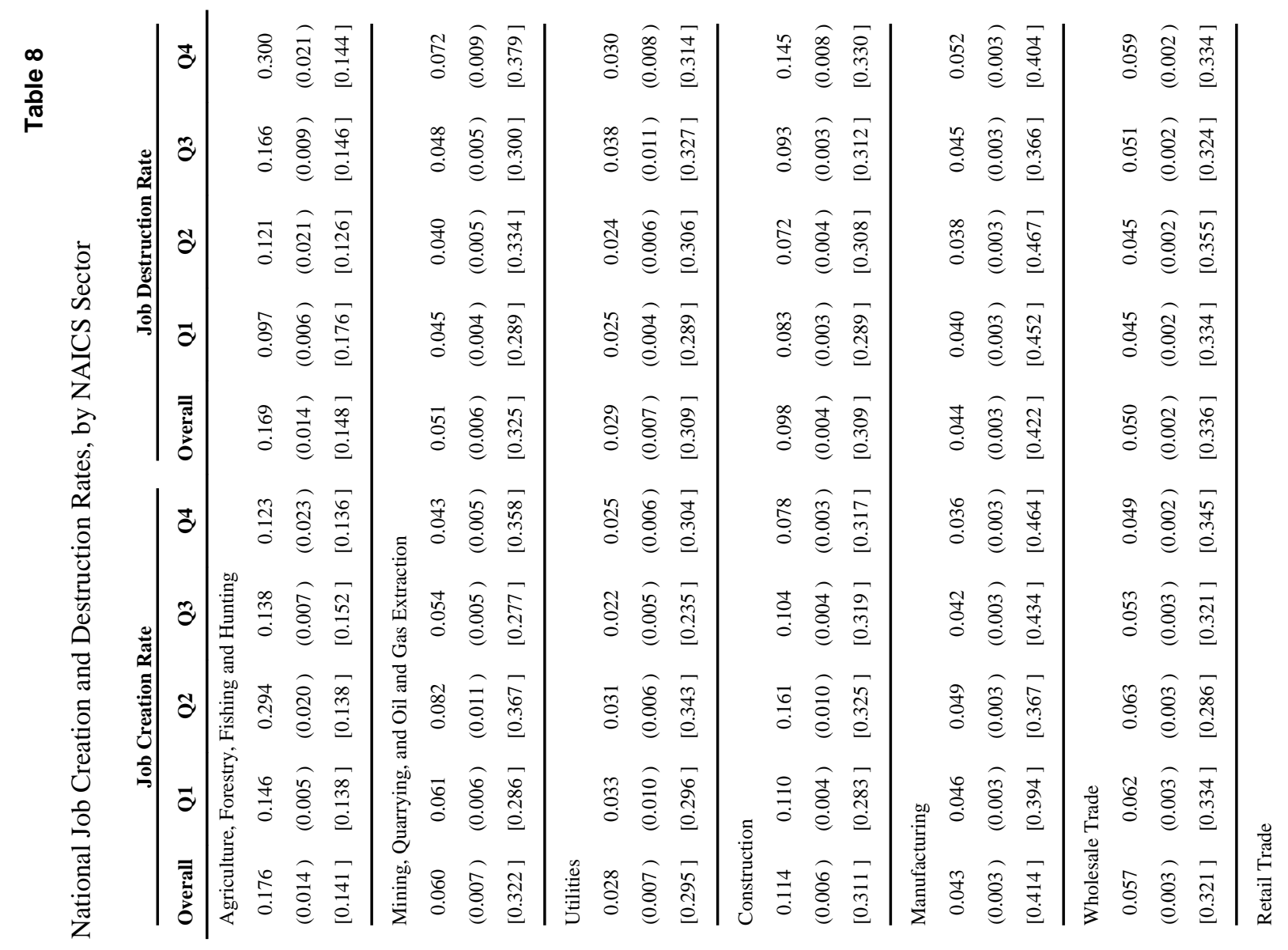




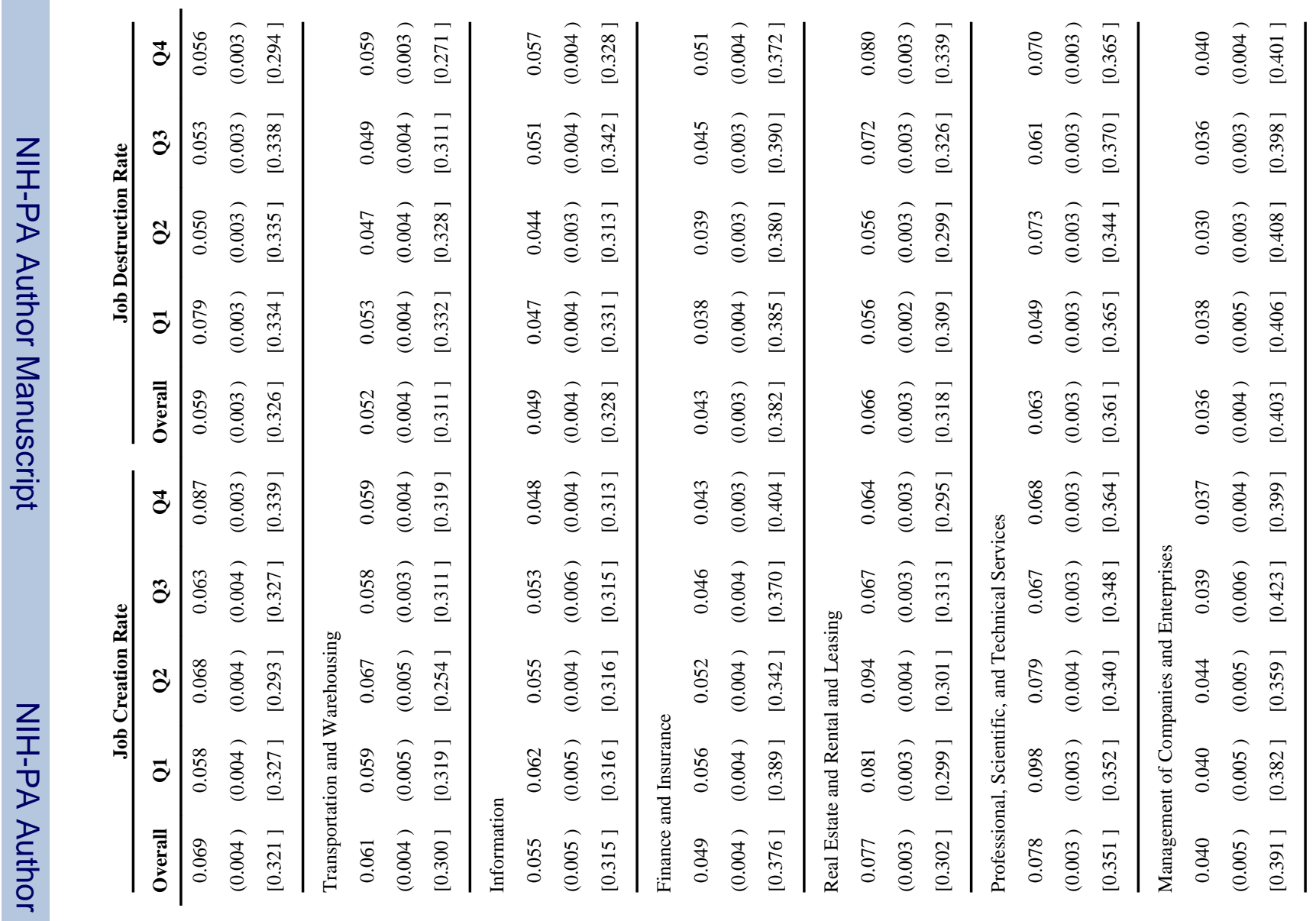




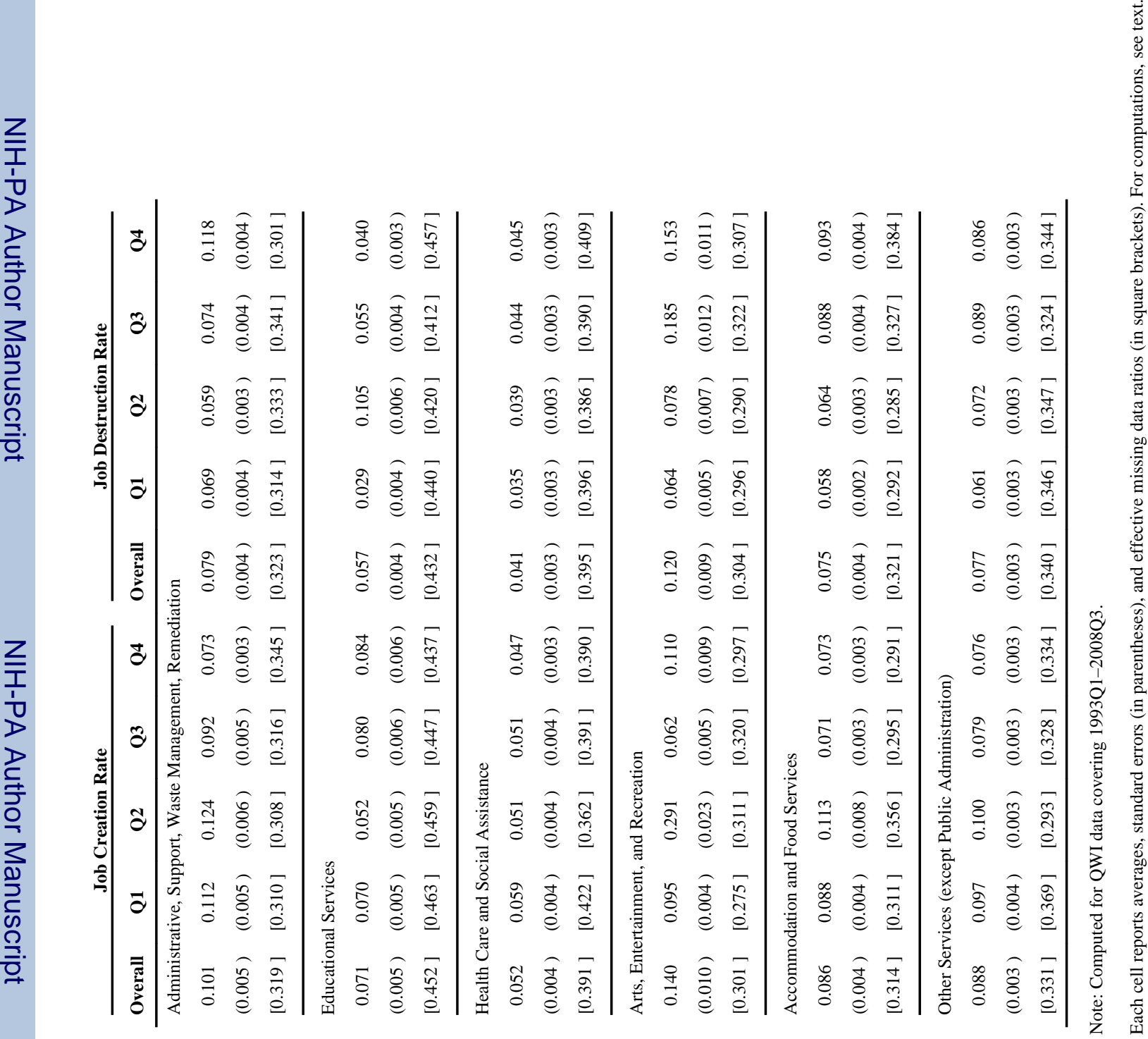

